\title{
GROUP COUNSELING AS AN INTERVENTION IN ANGER EXPRESSION AND DEPRESSION IN OLDER ADULTS
}

\author{
DISSERTATION \\ Presented to the Graduate Council of the \\ University of North Texas in Partial \\ Fulfiliment of the Requirements
}

For the Degree of

DOCTOR OF PHILOSOPHY

By

Wanda $Y$. Johnson, B.ED., M.ED. Denton, Texas

December, 1988 
Johnson, Wanda Y., Group Counseling as an Intervention in Anger Expression and Depression in Older Adults. Doctor of Philosophy (Counseling and Student Services), December, 1988, 98 FP., 24 tables, bibliography, 81 titles.

Depression is believed to be the most prevalent mental dysfurction among older adults, and depression and anger are frequently linked in theory and in therapy. This study was undertaken to determine whether participation in group counseling sessions would increase awareness and expression of anger and decrease depression levels in women aged 65 and older. Treatment group members were compared to a matching control group. Both groups completed the Anger Self Report Questionnaire and the Beck Depression Inventory. Comparison of the ASR subscale scores, Awareness of Anger, Expression of Anger, Guilt, Condemnation of Anger, and Mistrust, revealed no significant differences between the treatment and control groups. However, the treatment group scored significantly higher on the BDI than did the control group.

Analysis of variance of the ASR and the BDI, and the variables upon which the treatment and control groups were matched revealed some significant differences, and comparison af the women in this study with the two groups upon whom the ASR was validated showed this study's older women scared significantly lower than the validation groups on the ASR. 
The author concluded that six sessions is not long enough to effect change in either anger awareness or expression in older women, and more time is needed to establish group cohesiveness in older populations than that yeneraly thought to be needed for younger populations. Replication of the study with men and women, and replication of the study using a longitudinal design is recommended in order to determine whether awareness and expression of anger change with age, or whether differences between older and younger populations are due to historical and environmental influences. 
TABLE OF CONTENTS

LIST OF TABLES. . . . . . . . . . . . . . . . Page Chapter

I. INTRODUCTION . . . . . . . . . . . . . . . 1

Statement of the Problem

Synthesis of the Literature

Research on Anger Regulation

Summary

II. PROCEDURES. . . . . . . . . . . . . . . 21

Definition of Terms

Hypotheses

Subjects

Instrumentation

Treatment

Collection of Data

Procedures for Data. Analysis

II. RESULTS AND DISCUSSION . . . . . . .

Analysis of Data

Follow-Up Data

Additional Analysis of Data

Comparison with ASR Validation Groups

Summary of Results

Discussion

Related Findings

Conclusions and Recommendations

APPENDIX . . . . . . . . . . . . . . . 73

REFERENCES. . . . . . . . . . . . . . . . . . . 89 


\section{LIST OF TABLES}

TABLE

Page

1. Number of Women in Treatment and Control

Groups Matched on Age, Marital Status,

and Type of Residence. . . . . . . . . . .

2. Number of Women in Treatment and Control

Groups Matched on Perceived Health,

Hollingshead's Occupational and Educational

3. T-test of the mean Differences Between

the Treatment and Control Groups on

the Beck Depression Inventory. . . . . . .

4. T-test Analysis of the ASR Awareness of

Anger Subscale.

5. T-test of the mean Difference Between

Treatment and Control Groups on ASR

Total Expression of Anger Subscale. . . .

6. T-test of the mean Differences Between

the Treatment and Control Groups on the

ASR Guilt Subscale. . . . . . . . . . . . .

7. T-test Analysis of the Mean Differences and Control Groups on the ASR Condemnation

of Anger Subscale . . . . . . . . . . . . .

8. T-Test Analysis of the Mean Difference

Between Treatment and Control Groups on

the ASR Mistrust Subscale. . . . . . . . .

9. T-Test Comparison of the Means of the

Treatment GRoup Scores on the ASR

Immediately Following the Sixth Group

Meeting and One Month Later . . . . . . . .

10. Paired Samples $\mathrm{I}$-Test of the Post-treatment and One Month Follow Up Treatment Group

Scores on the BDI... . . . . . . . . .

11. Analysis of Variance of General Expression

of Anger and Age. . . . . . . . . . . . . 


\section{LIST OF TABLES CONTINUED}

TABIE

Page

12. Analysis of Variance of the Beck Depression Inventory and Age.

13. Analysis of Variance of Educational

Level and ASR Guilt Subscale. . . . . .

14.. Analysis of Variance of Marital Status and

the Mistrust Subscale of the ASR. . . . .

15. Analysis of Variance of Type of Residence and Condemnation of Anger Subscale. . . .

16. Analysis of Variance of Perceived Health and the Condemnation of Anger Subscale of the ASR.

17. ASR Means and Standard Deviations for Treatment and Control Groups and for Zelin, Adler \& Myerson's Validation

Sample.

18. Results of the Multiple Range Test for

Awareness of Anger.

19. Results of the Multiple Range Test for

General Expression of Anger . . . . . . .

20. Results of the Multiple Range Test for

Verbal Expression of Anger. . . . . . . .

21. Results of the Multiple Range Test for Guilt

22. Results of the Multiple Range Test for Condemation of Anger . . . . . . . . . . .

23. Results of the Multiple Range Test for Mistrust.

24. Results of the Multiple Range Test for Total Expression. 
CHAPTER I

\section{INTRODUCTION}

The study of aging and health of older adults has important implications for our society in view of the increasing size of the aging population. Population projections indicate both a numerical and proportionate increase in people aged 65 and older. By 1990 it is estimated that there will be more than 13 million people aged 75 and older; by the year 2000 this number will exceed 17 million; and by 2025 this age group will be comprised of more than 25 million persons. The aged 85 and over population, about 2.3 million in 1980 , is projected to exceed 7 million by the year 2025 (Brody, 1985).

A major concern regarding the older adult population is the incidence of depression. Though difficult to assess, some authorities believe depression is the most prevalent mental dysfunction in older adults (Epstein, 1976; Gurland, 1976; Salzman \& Shader, 1978; Zarit, 1980). The prevalence of depression and the high suicide rate among older adults (Miller, 1979; Wenz, 1980) appears to warrant further study of depression in adults of this age group.

Anger and depression are commonly linked with the belief that depression results from the inability to express 
anger, In explaining the expression of anger, Novaco (1979) concluded that when people perceive they have little control over a situation, withdrawal and helplessness are likely to be the chosen behavior. Conversely, when people perceive they have some control, anger is the more likely expression, i. e. anger expression is an available coping mechanism which people believe will achieve a desired outcome. According to Novaco's theory, the diminishing control experienced by older adults tends to inhibit the expression of anger, and consequently causes a higher a higher level of depression.

There is a paucity of research on anger in general and about the reaction of older adults to anger and depression in particular. The social attitudes toward anger among older adults are conflicting. One stereotyped view of older adults describes them as irritable and cantankerous (Rogers, 1979), while another, the "tranquility myth," views old age as a "time of idylize serenity and tranquility" (Butler \& Lewis, 1977, p. 25). Dean (1962) found a decline in affect among older people; however, little empirical evidence exists to verify if affect declines, or whether there is a change in anger expression as people grow older.

Novaco (1977) called the lack of research on the emotion of anger a puzzling state of affairs, and Rothenberg (1971) cited widespread clinical treatment of anger and anger related froblems as evidence that anger research is 
needed. Difficulty in defining anger; in separating anger from aggression, hostility or other emotions; and the lack of adequate instruments to measure anger have thus far discouraged anger research (Biaggio, 1980; Rothenberg, 1971; \& Sarason, 1961). Little research on anger in the aged has been reported since 1970, a fact which Altholz (1982) attributed to researchers' concentrating on other social issues of the aged that seemed more urgent in the $1970^{\prime} \mathrm{s}$.

Despite this void in research, the available literature suggests a strong link between anger and both the mental and physical health of older adults. For example, failure adequately to deal with anger appears to play a part in increased mortality of the aged. In a study of elderly who moved from one convalescent home to another because their former home closed, Aldrich (1964) found that four times as many people described as angry and demanding survived the critical first three months in the new residence as opposed to those not characterized as making "angry adjustments." Further evidence of the survival value of anger expression was revealed in a study by Turner, Tobin and Lieberman (1972), who found anger to be one of the adaptive traits of people who survived their first year in an institution. Subjects characterized as "aggressive" appeared to profit most from individualized treatment programs devised to help them improve functioning in their respective areas of excess 
disabilities (Kleban \& Brody, 1972).

Cardiovascular disease, which includes hypertension, is the fourth leading cause of death in the United States. Busse and Blazer (1980) discussed the relationship of hypertension and anger in the aged and suggested that in the predisposed individual, inhibition of anger, aggression and resentment seemed to be linked to hypertension. Henry (1976) also found a link between hypertensian and aggression. In his studies of hypertension in mice, he concluded that those able to influence the outcome of life events exhibit aggression in the face of challenge, while those with no control evince signs of depression. Though both groups of mice died earlier than expected, the mice with no control died first.

Our society appears not only to devalue the status of older people, but also to inhibit their ability to influence their lives and to express their emotions, including anger (Belsky, 1984). With the loss of social status, the older person also loses the privileges associated with that status, such as the privilege of becoming angry. Repressid anger in the predisposed individual may be emotionally and physically debilitating. Encouraging the expression of anger and allowing older adults control in their lives may offset the toll taken by depression. Several studies show that group counseling and training can be used effectively to help people appropriately express anger (Hasterok, 1973; 
Hazaleus \& Deffenbacher, 1986; Hoffman, 1978; Novaco, 1979), and reviews of the literature on counseling techniques with older adults reveal group counseling techniques successfully improve adjustment and improve the quality of life of older adults (Medler, 1980; Sargent, 1982; \& Wellman \& McCormick, 1980). The view of anger taken in this study was that espoused by Novaco (1979); anger inhibition is not as important as the ability to express anger in appropriate ways. Indeed, suppression of anger is viewed as harmful to the individual. Therefore, a training program designed to increase awareness of anger, and also increase expression of anger, was postulated to decrease depression.

Statement of the Problem

Depression is a frequent and debilitating condition affecting older adults, and although the available literature suggests a probable link between depression and unexpressed anger in older adults, very little research has been conducted to examine the effect of a change in anger expression upon depression. Therefore, this study investigated whether an anger training program for older adults affected their awareness of anger, expression of anger, and level of depression.

Synthesis of the Literature Although several theorists and a few researchers have 
examined the relationship between anger and depression, results have been equivocal. Unexpressed anger is Iinked to depression by several theorists. Psychoanalysts first espoused the theory that depression is caused by anger turred inward against the self rather than directed outwardly (Freud, 1917; Menninger, 1938). Ferster (1973) also theorized that anger and depression are causally linked. He compiled a behavorial analysis of depression and depicted anger as creating a loss of reinforcers for the person because significant others withdraw from anger and the depressed/angry person becomes more isolated. According to Ferster, expression of anger is repressed when such expression leads to punishment or lack of reinforcement, and repression of anger leads to depression by causing such a large part of a person's repertoire of energy to be comitted to activities (repression) which do not produce positive reinforcement.

Goldfarb (1975) also identified anger as a factor in depression; however, he described depression as an elderly adult's effort to force others to come to the aid of the elderly person. Goldfarb's theory of depression identified the intrapunitive elements of depression as self depreciation, retrospective falsification of a self-derogatory nature and retroflexed rage with guilt, shame and feelings of humiliation.

Dean (1962) included the four states of irritation, 
anger, horedom and loneliness in an investigation of social-psychological factors accompanying the transition from middle to old age in a panel of 200 men and women aged 50 to 95. Dean posited that, on the basis of physical and intellectual decline with age, there would be a corresponding decline in the ability to feel emotion. Asked how often and when they were more likely to feel anger, subjects over age 60 showed an abrupt drop in reported anger. Subjects seemed to think irritation was the more acceptable feeling and perceived anger as a lack of control. Dean concluded that the more active emotional states declined with age.

In reporting on the Dean study, Altholz (1982) noted a possible bias toward the disengagement theory of aging, since Dean drew her data from the Kansas City Study from which the theory of disengagement was formulated. The disengagement theory holds that an inevitable diminished emotional energy in old age causes people to withdraw wilingly from interpersonal interaction.

In a study of anger in the aged, 140 adults who were selected as psychiatrically normal controls for a study of subjects with psychotic depression were divided into two groups by age (Friedman \& Granick, 1963). Seventy-four of the subjects were in an aged 45 to 65 group and 66 were in an aged 66 to 85 age group. The authors asked subjects if they believed it were ever right to be angry, asked them to 
describe the last time they were angry, and administered the Clyde Mood Scale on which the authors analyzed five moods characterized as rebeliious, furious, nagging, rude and violent. Results showed a significantly greater frequency of the over 65-year-old group to deny that it was ever right to be angry; yet, these subjects described themselves as furious significantly more often than the younger age group. Women of both age groups revealed more disapproval of anger than men; however, the older men in the sample showed more disapproval of anger than the younger men in the sample. Friedman and Granick concluded that men's attitudes toward anger change more than women's attitudes in old age, with men becoming more disapproving of anger as they age. The authors considered cultural change and the effects of the aging process as possible explanations for the differences in the two age groups.

Friedman (1970) designed a study to determine whether charges in aggression and hostility were correlated with clinical improvement in depressed patients. Subjects were 213 patients who were part of a group selected for the Collaborative National Institute of Mental Health Psychopharmacology Depression Study by 10 hospitals who participated in the study, and a non-depressed control group composed of volunteer subjects from the community. Subjects completed the Buss-Durkee Hostility Inventory in the pretreatment phase of hospitalization and again at 3,5 , and 
7 weeks of treatment. The BDHI assesses eight types of hostility: assault, indirect hostility, irritability, negativism, resentment, suspicion, verbal hostility and guilt. Subjects also completed a measure of self-rating of improvement in depressive symptoms.

Friedman concluded that the most interesting finding of his study was that severely depressed patients reported less Verbal Hostility than non-depressed individuals, but they reported even less verbal hostility as they improved, thus they deviated further from the norm when improved than when depressed. Depressed patients were not found to have a higher degree of internalization of hostility than the nondepressed control subjects; however, they did have a higher degree of resentment, and when Friedman considered the interrelationships of hostility variables within the patient sample, internalization, of all the seven subtypes of hostility, had the highest significant correlation with degree of depression scores and with degree of guilt-worthless scores. Also, a significant correlation was found between decrease in internalization scores and clinical improvement or lifting of depression.

Gershon, Cromer and Klerman (1968) used Gottschalk's Hostility Scales to analyze verbal productions of six female patients hospitalized for depression. Ratings on the hostility scales measured hostility-in, hostility-out, and ambivalent hostility, and these ratings were correlated with 
a Depressive Symptoms Scale which measured the depth of depression. The authors concluded that there were two different classifications of patients because two patients manifested hysterical personality features while the other four did not. In both groups, high hostility-in was associated with clinical depression while in the patients with hysterical personalities, hostility-out was found to increase with deepening depression and subside with improvement in depression. In the other four patients, the authors found no relation or a low negative relation between hostility-out and clinical affect.

In a study designed to examine the extent to which inward and outward directed hostility determine clinical depression, Rahdert (1980) adminstered the Beck Depression Inventory and used the Gottschalk-Gleser method of verbal content analysis to define the direction and intensity of verbal hositlity. During several months of treatment, she repeatedly measured depression and hostility direction in 11 clinically depressed women in outpatient treatment at a mental health center clinic. Rahdert also administered each measure to nine nonpatient women. Contrary to expectations, the author found significantly high levels of outward-directed hostility in the clinically depressed women. These levels remained high throughout the several months of treatment, while there was a demonstrable downward trend in the levels of inward-directed hostility and 
depression. The nonpatient women had an equally high level of outward-directed hostility and their inward-directed hostility level was slightly higher than the depressed patients. Though the research disconfirmed the model of depression as a result of anger turned toward the self, Rahdert suggested that many of the verbal expressions labeled inward-directed hostility might reflect fear or a lack of aroused pleasure, rather than aroused anger.

Dean (1980) based a study of anger and depression on Epstein's theory that depression results when angry feelings are considered unacceptable and are not expressed; instead, the individual devalues the self in order to avoid disapproval by others (Epstein, 1973). Dean investigated whether aversion to hostile or angry feelings predisposed undergraduate college students to depressive experiences and hypothesized that subjects with negative attitudes toward, or greater discomfort with anger would report more depressive experiences on the Beck Depression Inventory. Dean used four measures to assess reactions to anger: (a) subjects' ratings, on a comfortable/uncomfortable dimension, of anger expressed by actors on videotape; (b) measurements of subjects' gestural and postural expressions of discomfort while viewing the videotapes; (c) semantic differential rating scales measuring subjects" constructs about anger and other feelings; and (d) subjects' self-report of the frequency of their expressing anger. Although results were 
nonsignificant, the obtained correlations of BDI scores with the discomfort self-report, gestural and postural measures and anger self-report were in the predicted direction.

Noel (1980) investigated two models of depression:

(1) depression caused by anger turned inward against the self; and (2) the learned helplessness model which claims that lack of control over important autcomes results in helplessness and depression, that attributions made about one's helplessness determine the extent of the depressive deficits, and that controllability (the experience of having control over outcomes) treats helplessness and depression. Noel divided 70 undergraduate students into nondepressed and depressed groups. Prior to the experimental treatments, nondepressed-made-helpless subjects were given unsolvable cognitive problems to induce helplessness. Helpless and depressed subjects then participated in one of three diadic role playing treatment conditions: (a) effective anger, in which subjects expressed anger and experienced controllability; (b) cathartic anger, in which subjects expressed anger but did not experience controllability; and (c) inhibited anger, in which subjects neither expressed anger nor experienced controllability.

According to the learned helplessness theory, Noel (1980) predicted that helplessness induction would lead to increased depressed affect because of exposure to uncontroliable outcomes, and further, that controllability 
(Effective Anger) would alleviate helplessness and depression. Moreover, based on the learned helplessness theory, Noel predicted depressed and nondepressed subjects would have different attributions for success and failure. The hostility-in model predicted that catharsis alone would treat depression. The measures used were the Depression Adjective Check List, an anagrams task and an attributional style questionnaire. Results showed that the anger-turnedinward model was not confirmed, since for depressed subjects, only the effective anger treatment led to a significant decrease in depressed affect. Depressed cathartic anger subjects showed variable affective responses following treatment, but inhibited anger subjects tended to become more depressed. Disconfirming the learned helplessness theory, nondepressed subjects did not significantly increase depressed affect in the helpless group.

Studying the association between hostility and depression, Schless, Mendels, Kipperman, \& Cochrane (1974) distinguished between the relationship of hostility and depression during the depressed phase and the relationship prior to the development of depression. Thirty-seven Fatients classified as depressed, between the ages of 28 and 56 years, were investigated on several measures of hostility and depression soon after admission to the hospital. Using the Eactor analysis principal component method with 
orthogonal rotation, the authors found that five factors accounted for $62.4 \%$ of the total variance. Four general patterrs emerged from the factor analysis: (a) anxious, guilt-ridden, inward turning of hostility with resentment (Factor 1); (b) verbal hostility with negativism (Factor 2); (c) anxious, suspicious, resentful, control of hostile feelings (Factor 4); and (d) assaultive, verbally abusive outward expression of hostility (Factor 5). Schless and his associates explained that they found Factor 3 to be a somatic factor accompanied by withdrawal, which was difficult to interpret because of the paucity of scales loading on it. Results further demonstrated that the most severely depressed patients showed both more inwardly and outwardly directed hostility. Increased hostility in the patients took the form of resentment and the authors interpreted this finding to suggest that highly depressed people may see other people's anger as more potent and may be afraid to show their own anger for fear of retribution. Therefore, resertment becomes the only safe means of expressing hostility.

Weissman, Klerman, and Paykel (1971) compared multiple assessments of hostility in 40 depressed women with 40 nondepressed women. Experienced psychiatrists interviewed the patients, rated the patients' hostile behavior, and analyzed patients' feelings toward others. Depressives showed low hostility to therapists, but high 
levels of hostility to others, especially those closest to the patient--children and spouses. The authors discussed the increased hostility with intimate associates and postulated that the depression occurs when the individual cannot directly express anger toward disappointing love objects for fear of losing their support. The authors further suggested that effective treatment might be directed toward helping the depressed person acknowledge and come to terms with anger and the origin of anger rather than acting out the anger.

Winefield (1981) studied anger expression in health and illness in a group of healthy students, a group of hospitalized depressives, and a group of parents of seriously ill children. The control group consisted of 65 older students (average age 26.5 years), 35 women and 30 men. These subjects included 11 parents, none of whose children had suffered significant health problems in the previous two years. The parent group included 21 mothers and 15 fathers with leukenemic children. Average age of the parents was 34.2 years. Thirty women (average age 33.3 years), hospitalized and diagnosed as depressive were the third group. Winfield adminstered the Rosenzweig Picture-Frustration Study to all three groups, and she administered the Nowicki Strickland Internal External Locus of Control Scale and the Self-rating Depression Scale to the depressives and to the students, but not to the parents. 
Winefield hypothesized that if people undergoing severe stress suppress anger, there might be a negative correlation between the extragression (E score--aggression turned anto the environment), and feelings of lack of control (externality) and possibly between E scores and depression. Results revealed no significant age or sex differences. Outer-directed aggression was negatively related with both externality and depression, and imaggression (M score--aggression evaded by denial of the frustration) was positively correlated with depression. Reported outerdirected hostility scores were lower in parents of leukaemic children and in hospitalized depressives than in healthy older students. Winefield concluded that a certain amount of outer-directed hostility is a healthy sign and she equated this outer-direction of hostility with assertiveness. In a study of anger, using self-report questionnaires and 521 subjects aged 21 to 60 years, Averill (1982) concluded that both the person expressing anger and the person who was the target of the anger perceived the short term consequence of expressing anger as unpleasant. However, both the person expressing anger and the person who was the target of the anger viewed the long term consequence of expressing anger as positive and beneficial to relationships. Averill also examined gender differences in the everyday experience of anger and found that men and women became angry about equally often, for about the same 
reasons and with about equal effect. According to his studies, greater differences exist between individuals within each gender than between genders.

Altholz (1982) reviewed the existing theories and research on anger in the aged and arrived at several theoretical conclusions about the nature of anger in the aged. She outlined the proposition that anger arousal in the aged is lessened because of physiological changes in the brain, the endocrine system and autonomic nervous system. The less efficient functioning of these systems cause the older person to cognitively interpret and label a milder emotion such as annoyance or irritation, rather than anger. Studies showing that it takes more time for older adults to return to homeostasis once aroused suggested that fear of overarousal is associated with anger in older adults. Environmental and societal factors also may affect anger expression in older adults. Negative stereotypes, perceived low status and perceived lack of social support were suggested as inhibitors of anger expression. Older people may also regard angry behavior as ineffective in producing desired outcomes, especially in a restricted environment.

\section{Research on Anger Regulation}

Several studies reveal that the use of therapeutically designed self-instruction can serve as a means to regulate arger. Hazaleus and Deffenbacher (1986) found cognitive and 
relaxation group treatments effective in anger reduction among volunteers from an introductory psychology class who were found to have high levels of anger. No effects were found for depression, perhaps because the sample was initially low on depression. Training in cagnitive coping skilis for anger reduction had the added advantage of assisting subjects to also reduce general anxiety. Novaco (1979) compared effectiveness of cognitive coping and of relaxation training, separately and in combination, in increasing personal competence, managing provocations, and regulating the arousal of anger. He found combined treatment most effective and the cognitive next in effectiveness, followed by the relaxation group. All three treatment groups showed significant improvement over the control group.

According to Novaco (1979), the stress inoculation approach to anger management tends to prevent anger from occurring when it is maladaptive, to enable the client to regulate arousal and its concomitant cognitions when provocation occurs, and to provide the person with the behavioral skills needed to manage the provocation experience. Rather than attempting to inculcate suppression of anger, the therapy attempts to minimize the maladaptive Effects of anger and to maximize the adaptive functions.

Hoffman (1978) compared affect assertion training: insight therapy and ward milieu group treatments of 54 
psyohiatric inpatients and found that affect assertion training resulted in significant improvement of the Hy scale. of the MMPI. Both the affect assertion training and the insight therapy groups showed significant decreases on the $P$ scale of the MMPI.

Moon and Eisler (1983), compared the effectiveness of four experimental groups in reduction of anger. Each group had 10 subjects per graup, a problem solving group, a social skills group, a cognitive behavior modification group and an attention control group. Moon found problem solving, social skills and cognitive behavior modification approaches to anger control all successful in reducing anger, however only the social skills and problem solving groups were successful in increasing assertive behaviors. The author concluded that the cognitive apprach appeared to teach a passive strategy for anger reduction.

\section{Summary}

Anger has not been well researched and studies on anger in older adults are too scarce to allow conclusions to be drawn. Research on anger in younger populations suggests that both inward- and outward-directed hostility are connected to depression. Depressed people show high levels of hostility toward intimate associates and outer-directed aggression is negatively correlated with externality and depression. Aggression evaded by denial of the frustration 
is correlated with depression. The long range consequences of expresing anger are deemed to be positive both by people expressing anger and by those who are the target of anger. No significant gendex differences are found to exist in anger expresion, although men and women seem to have different goneeptions of what constitues provocation to anger. Older adults may experience anger differently than younger adults, however insufficient empirical evidence exists to reach any conclusions on the experience or expression of anger in older adults.

Research indicates that anger awareness can be increased, and that anger expression can be positively directed, in group training and counseling sessions. Research also indicates that older adults can benefit from group treatments such as cognitive group interventions, relaxation training and assertiveness training. 


\section{FROCEDURES}

This ohapter desoribes the definitions of tarme, hypotheses, selection of subjects, instruments used, and the procedures for the collection and analysis of data. It also identifies the rationale for selecting variables on which the control and treatment groups were matched.

\section{Definition of Terms}

The following operational definitions apply to terms as they will be used in this study.

Anger--The model of anger used by Novaco (1978) whereby anger is seen as determined by external events, internal processes, and hehavioral reactions was used in this study. Anger was operationally defined as those traits measured by the subscales of the Anger Self Report: Awareness of Anger, Expression of Anger, Guilt Associated with Anger, Condemation of Anger, and Mistrust or Suspicion. Depression--the scores individuals obtained on the Beck Depression Index.

Older adults--adults aged 65 years and older. Community living adults--adults living independently, and assuming the majority of responsibility for their own care, whether living alone or with others. 
Hypotheses

Due to the exploratory nature of this study, hypotheses were stated in the null form.

1. No significant difference will exist between the post test scores of the treatment and control groups on the Beck Depression Inventory.

2. No significant difference will exist between the post test scores of the treatment and control groups on the Awareness of Anger subscale of the ASR.

3. No significant difference will exist between the post test scores of the treatment and control groups on the Total Expression of Anger subscale of the ASR.

4. No significant difference will exist between the post test scores of the treatment and control groups on the Guilt subscale of the ASR.

5. No significant difference will exist between the post test scores of the treatment and control groups on the Condemnation of Anger subscale of the ASR.

6. No significant difference will exist between the post test scores of the treatment and control groups on the Mistrust or Suspicion subscale of the ASR.

\section{Subjects}

Subjects for the treatment groups in this study were 17 women aged 65 and over, from senior citizen centers and from retirement centers in the North Texas area. Men were not 
included in the study because research suggests that women share with each other more in all-women groups, while in mixed gender groups women have minimal contact with each other and allow men to dominate the group discussion. Women in groups with men tend not to assert themselves or assume leadership (Aries, 1976).

A matching frequency distribution control group (Bailey, 1978) of 17 members was chosen for the study. Members of the treatment groups ranged in age from 65 to 95 years, with a mean age of 76.2 , and women in the matching control group ranged in age from 65 to 85 years with a mean age of 74 years. Groups were matched on age, marital status, education, occupation, type of residence and perceived health.

Participants were matched on age by using equal numbers of women aged 65 to 75 and women aged 75 and above. This type of age classification was based upon a report by the Subcomittee on Human Services of the Select Committee on Aging, U. S. House of Representatives which suggested that there are two natural seasons of life--senior adulthood, about ages 60-75, and elderhood, 75 yearst. The committee determined that those adults in the senior adulthood ages were functionally independent, while those in the $75+$ age groups were more dependent and more likely to be in need of special care (Nelson, 1982).

Marital status was used as a basis of olassification 
because it is widely implicated as a factor in life satisfaction studies in older adults and life satisfaction is considered an important measure of adjustment or mental health (Edwards \& Klemmack, 1973; Palmore \& Luikart, 1972). Widowhood and divorce are seen as negative life events and the greater the number of negative life changes one suffers, the lower life satisfaction seems to be (Zeigler $\alpha$ Reid, 1983). The number of negative life events one suffers also seems to be associated with depression (Zarit, 1980).

Lopata (1978) found education and social class important variables predicting a widow's overall adaptation to life without her husband. The least educated, lower class widows were likely to be dissatisfied and socially isolated.

Education, occupation, place of residence, and perceived health are also included in studies of life satisfaction correlates (Edwards \& Klemmack, 1973; Palmore \& Luikart, 1972; Zarit, 1980) and were variables upon which the treatment and control group were matched for this study. In a study of 502 community residents aged $45-69$ years, Palmore and Luikart (1972) found self-rated health the predominate variable influencing life satisfaction in early and late middle age. When Edwards and Klemmack (1973) held socioeconomic status constant in their study of 274 women and 233 men aged 45 years and over, the relationships botween life satisfaction and age, marital status and family 
size disappeared and the best predictors of life satisfaction were socioeconomic status, perceived health and informal participation with nonkinsmen. Hale (1982) also found physical health to be related to depression in 68 (47 women and 21 men whose ages ranged from 63 to 94 years) residents of a retixement center for both men and women. In addition, Hale found financial status related to depression among women.

Health, marital status, educational level, and cccupational level also seem to relate to depression in some older people. Blazer, Hughes and George (1987) studied differences among people aged 65 and over who exhibited depressive symptomatolagy and people in this age range who did not exhibit depression symptomatology. They concluded that the depressed sample differed from the overall sample in that they were likely to be in poor physical health, female, somewhat less educated, not married, and of a slightly lower socioeconomic status.

Though some evidence of a preference for housing among age-peers is evident in all age groups, studies on how housing affects life satisfaction are inconclusive (Zarit, 1980). Whether older people are happier in age-segregated housing or in houses and apartments in a diverse community setting cannot be specified because of the number of variables affecting the choice. Type of residence was used as a matching variable beoause of the fogatide influmos 
upon life satisfaction and depression. Type of residence was classified by whether participants lived in a house, apartment, or retirement center apartment. Two members, one in the treatment group and one in the matching group, lived in a duplex. For purposes of this study, duplexes were classified as houses. In addition, participants were asked whether they lived alone, or with someone. Only two of the unmarried participants lived with sameone else.

Hollingshead's categories of education and occupations were used to classify the educational level and occupation of each of the participarts (Hollingshead, 1975). Hollingshead ranked occupations from a 9, consisting of higher executives, proprietors of large businesses and major professionals; to a 1, consisting of farm laborers and menial service workers. Occupational levels are keyed to the occupational titles used by the United States Census in 1970. Hollingshead used the occupation of the deceased spouse during the time of gainful employment to determine occupational levels of widows or widowers who are not gainfully employed. Retired persons occupational levels are computed on the occupation of that person or that person's spouse, before retirement. Educational levels were ranked on a scale from: 1, less than seventh grade education; to a 7, graduate professional training. Educational and cocupational classification lists are in the Appendix. Table 1 shows the number of women in the treatment and 
control groups in the Age, Marital Status and Type of

Residence categories. Table 2 shows the number of women in the treatment and control groups in the Perceived Health, Occupational and Educational Categories.

Table 1

Number of Women in Treatment and Control Groups Matched on Age, Marital Status, and Type of Residence

\begin{tabular}{lccccccccc}
\hline & Age & $\begin{array}{c}\text { Marital } \\
\text { Status }\end{array}$ & Type of Residence \\
\hline & -75 & +75 & M & W & D & House & Center Apartment \\
& 9 & 8 & 4 & 9 & 4 & 9 & 6 & 2 \\
\hline $\begin{array}{l}\text { Treatment } \\
\text { Control }\end{array}$ & 9 & 8 & 4 & 9 & 4 & 9 & 6 & 2 \\
\hline
\end{tabular}

Table 2

Number of Women in Treatment and Control Groups Matched on Perceived Health, Hollingshead's Occupational and Educational Status

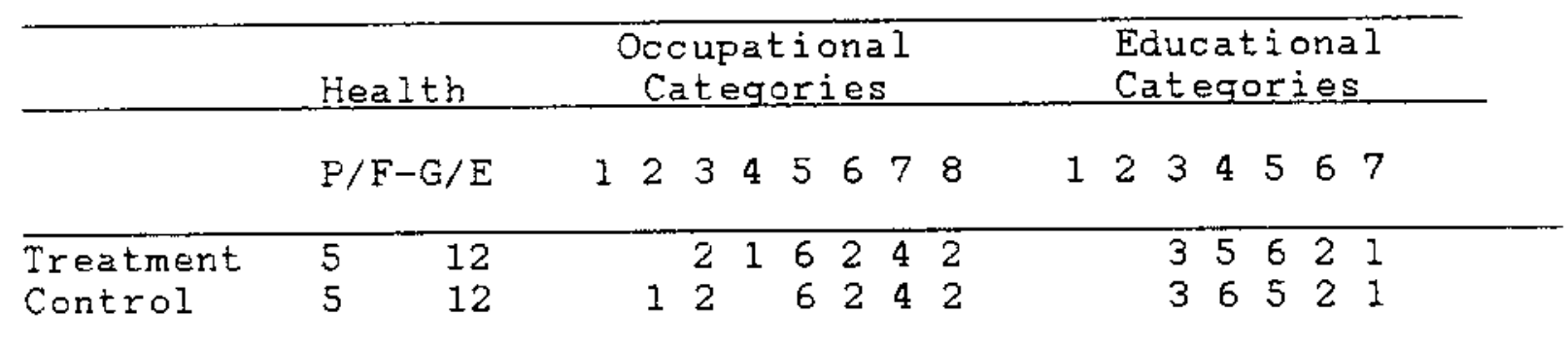

Instrumentation

Two instruments were used in this study. The Beck Defression Inventory (BDI) (Beck, Ward, Mendelson, Mock, \& 
Erbaugh, 1961) was used to measure depression. The Anger Self-Report Scale (ASR) (Zelin, Adler, \& Myerson, 1972) was used to measure awareness of anger, expression of anger, and guilt.

The BDI is a widely used 21 item self-report measure of the intensity of depressive symptomatology. Items consist of a graded series of four self-evaluative statements ranked to reflect the range of severity of the symptoms from neutral to minimal severity. Numerical values from zero to three are assigned each statement to indicate the degree of severity. The BDI is scored by adding up the encircled numbers. The higher the score the more depressed is the subject. Scores are classified with $0-9$ indicating no depression or minimal depression, 10-14 indicating borderline depression; 15-20 indicating mild depression, 21-30 moderate depression; $31-40$ indicating severe depression; and 41-63 indicating very severe depression (Beck, 1967).

Internal consistency for the BDI was determined by two methods. First, the score for each of the 21 items was compared with the total score on 200 BDI protocols. Correlations between each of the 21 items and the total scores were significant beyond the .001 level. Second, the split half reliability method using the same 200 protocals yielded a reliability coefficient of .93 with the Spearman-Brown correction (Beck et al., 1961). Construct 
validity was determined using the BDI as the criterion measure. A significant relationship was found between depression and masochistic dreams, scores on a self-concept test (high scores indicating low self-concept). childhood bereavement, and the tendency to underestimate actual task performance (Beck, 1967, p 203).

The BDI has been used extensively and continues to display a high degree of stability and internal consistency across various clinical populations. It appears to discriminate changes in depression produced by different therapies. This scale also is now used to screen for depression (Sartorius \& Ban, 1986). Lambert and his associates (Lambert, Hatch, Kingston, \& Edwards, 1986) used meta-analytic techniques to determine whether the BDI, the Hamilton Rating Scale for Depression, and the Zung Self-Rating Scale provide comparable data for assessing treatment effects. Their finding that the BDI and Zung Self-Rating Scale showed significantly less change in depressior following treatment than did the Hamilton Rating Scale For Depression, was analyzed and the authors suggested that these scales measure different aspects of depression. The BDI emphasizes the subjective experience of depression, including pessimism and self-puritive wishes. Only $29 \%$ of a BDI score may be attributable to a physiological factor whereas $50 \%$ to $80 \%$ of the Hamiliton Scale score is behavioral and physiological components. Therefore, the 
changes measured by the BDI, cognitive and affective changes, would be picked up after the changes measured by the Hamilton Scale, which first picks up changes in vegetative symptoms. Because this study does not purport to measure hefore and after treatment effects of depression, it was assumed that the BDI is an accurate measure of the subjects' perception of depression.

The BDI was found to reliably assess depression among people over age 60 (Gallagher, Nies, \& Thompson, 1983). Reliability was assessed in two older groups, a patient sample and a comparable nonclinical group of community volunteers. The BDI was administered twice to each group, with retest intervals ranging from 6 to 21 days apart. Patients were awaiting treatment for depression during the time of the reliability study. The mean age for the patient group was 67.8 years and for the volunteer group mean age was 69.9 years. Test-retest reliability coefficients for the total group were 90 , for the volunteer group .86 , and for the patient group .79. Split-half coefficients using Spearman-Brown correction were: Total group, .84, Volunteer group, .74, and Patient group, 58 . Results evaluated for the total sample and for the two groups separately suggested that the BDI has adequate internal consistency and stability for use with older adults and appears to be adequate as a clinical screening instrument for use with the elderly. 
Further support for use of the BDI on populations of older adults was found in an examination of the BDI cutoff scores. Gallagher and her associates (Gallagher, Breckenridge, Steinmetz \& Thompson, 1983) used a combination of selected Research Diagnostic Criteria for a current episode of Major Depressive Disorder and information derived from the Schedule for Affective Disordes and Schizophrenia to check cutoff scores on the BDI. They found the conventional cutoff scores, non-depressed (scores of 10 and less), mildly depressed (scores from 11-16), and moderately to severely depressed (scores of 17 or greater), to be appropriate for identification of depressive disorders in older clinical samples. The low rate of false positives was deemed to be due to older people's tendency to downplay or deny symptoms on a self report check list (Gallagher, Breckenridge, Steinmetz, \& Thompson, 1983).

The Anger Self-Report Scale is an objective questionnaire for measuring awareness of anger, its expression in behavior, guilt, and mistrust. There are four main parts of the ASR: (1) awareness of anger,

expression of anger, (3) awareness of guilt, and (4) concomitants of aggression, specifically mistrust or suspicion. The 64 items of the scale are marked according to the amount of agreement or disagreement using a six point Likert type scale ranging from (+1) slight agreement to (-3) strong disagreement. The scale is scored according to a 
score sheet which lists the numeric value for agree and disagree items for each subscale. Items are then summed separately and the sum of the disagree items is subtracted from the sum of the agree items. The Awareness of Anger subscale consists of 13 questions, 5 agree questions and 8 disagree questions. There are three parts to the Expression of Anger subscale: General Expression of Anger, which consists of 9 items, 5 agree items and 4 disagree items; Physical Aggression, consisting of 5 items, 3 agree items and 2 disagree items; and Verbal Aggression which has 9 items, 5 agree items and 4 disagree items. To obtain Total Expression scores, the three subscale scores are scored and added together. The Guilt subscale contains 4 agree items and 5 disagree items. The Condemnation of Anger subscale has 5 agree items and 2 disagree items, and the Mistrust or Suspicion subscale has 7 agree items and 5 disagree items. The questionnaire was developed with 89 items, but following extensive item analyses based upon the first 138 questionnaires obtained, 25 items were omitted and 64 items were retained. The item analysis was based upon an examination of each item for its correlation with other items in the same scale and its correlation with the total score on the scale to which it belonged. The reliabilities of the eight ASR scales and their intercorrelations indicate sufficient independent, reliable variance so that an Anger Profile based on the eight ASR scores can be validly 
employed for predictions about individuals (Zelin, Adler, \& Myers on, 1972).

Validation studies were completed using samples of 82 psychiatric patients and 67 college students. In the patient sample, scores on the ASR were correlated with psychiatrists' ratings on the 16 most relevant Problem Appraisal Scales. A multitrait, multimethod of analysis of these correlations yielded substantial convergent and discriminant validities for the ASR scales. The highest correlation for the physical expression scale was with ratings of assaultive acts on the PAS (.41). The largest correlations for verbal expression were -.36 with dependency and .31 with anger, belligerence and negativism. Dependency was found to correlate significantly in a negative direction with the Expression scales, $(-.30, p<.05,2$ tail test, with general expression, $-.36, p<.01,2$ tail test, with verbal expression, and $-.24, p<.05,2$ tail test, with total expression). The correlations for the ASR scale of Guilt with the PAS ratings on Suicidal Thoughts was $.48, \mathrm{p}<.01,2$ tail test, on Suicidal Acts .24, on Depression-Inferiority .33 , and on Social Withdrawal .29. The latter three were significant at the .05 level in a two tail test. The ASR scores of 67 college students were correlated with six ratings made by three students living in the dormitories near the testees. The highest correlation for the awareness score was with the rating "To what extent does this person 
feel anger?" $\left(r=.20, \mathrm{p}^{<}, 01\right)$. The highest correlation with verbal expression was with ratings of the extent the testee "provoked arguments" $(r=.29, \mathrm{p}(.01)$. The authors reported that validities support the use of the ASR in further studies of aggression (Zelin, Adler, \& Myerson, 1972). Biaggio (1980) administered four anger scales to 72 men and 78 women students to determine correlations between the scales. The scales used were the Buss-Durkee Hostility Invertory (BDHI), Reaction Inventory (RI), Anger Self-Report (ASR), and Anger Inventory (AI). Correlations between BDHI Total Hostility and ASR Total Expression were significant $(r=.64, p(.01)$. The following correlations were also sigrificant at the .01 level: BDHI Total Hostility with ASR General Expression, Physical Aggression, and Verbal

Expression; BDHI Assault and Verbal Hostility with ASR Total Expression; BDHI Assault with ASR Physical Expression; BDHI Verbal Hostility with ASR Verbal Expression; BDHI Assaul, Indirect Hostility, Irritability, Negativism, Resentment, Verbal Expression, and Total Expression with ASR Awareness of Anger; BDHI Suspicion with ASR Mistrust; and BDHI Guilt with ASR Guilt.

Biaggio also correlated the BDHI, the Ri, the ASR and the AI with the Marlow-Crowne Social Desirability Scale. Significant negative correlations were found between Social Desirability and the ASR General Expression, Physical Expression, Verbal Expression, and Total Expression. 
Biaggio also found several correlations which attested to the validity of subscales of the ASR. The ASR scale, Condemnation of Anger, had an almost zero correlation with BDHI scales, slightly negative and nonsignificant correlation with the RI, and a negative and significant correlation with the AI, $(r=-.16, p(.05)$. Since this scale purports to measure negative feelings about anger, the lack of positive correlations with scales assessing expression or propensity for anger arousal attests to its validity. Biaggio concluded that the BDHI and ASR appear to be measuring similar variables, and reveal appropriate absence of correlation with dissimilar values. She attests to the concurrent and discriminant validity of these scales.

Though the ASR scale is in need of further validation, and has not been used with a population of older adults, it appears to be the most appropriate anger scale available for the purposes of this study. The BDHI is the most frequently used in research; however, it fails to distinguish between the awareness of anger and the expression of anger.

\section{Treatment}

Four treatment groups were conducted at four different sites. Each group was led by the examiner to control for differences which might result from using more than one therapist and also because much of the anticipated value of the study was to learn how women aged 65 and older 
experience and express anger. Anecdotal records of each session were kept and reviewed to determine common themes among group members. Each group met for 6 weekly 60 minute sessions. One make-up session was scheduled during the week following the fifth session for those who missed a session.

The treatment group followed a semi-structured group format incorporating techniques organized by the investigator from information found in the literature. Content of group meetings related to anger awareness, anger expression, and group techniques found to be effective with adult women. The general format for each session involved introducing topics for consideration and then allowing time for group members to respond and react. As in any group experience, members were encouraged to respond by expressing their thoughts and feelings. Following is a synopsis of each group session.

Session 1 - The session began with introductions, a discussion of the purpose of the group and confidentiality expectations of the group. The leader asked group members to describe an experience when she was angry, and to focus upon the feelings connected with anger. The leader also asked group members to recall how their parents expressed anger, and to decide which parent they most resembled in their experience and expression of anger. At the end of the first session, the leader requested that group members be 
aware of their own anger and that of others during the week.

Session 2 - The session began with members sharing their anger experiences of the past week and their observations of other people's expression of anger. The leader then asked members to talk about events which usually make them angry. The leader explained Ellis' Rational Enotive, ABC theory (Walen, DiGiuseppe, \& Wessler, 1980) and asked group nembers to respond to their perceptions of anger using Ellis' model.

Session 3 - The leader related an anger-provoking incident and asked group members to respond to it in terms of the degree of anger experienced and how they would feel and react in such a situation. The leader introduced the push-button technique (Mosak, 1984) and following the experience of controllability of feelings, the leader asked members to discuss the control they have over other events and experiences in their lives.

Session 4 - The leader introduced the session by asking members to recall how anger was expressed in their families of origin and to discuss the differences between men and women's experience and expression of anger. They also were asked to consider different family patterns of interaction and especially differences between their immediate family and their family of origin. The group was asked to brainstorm effective ways of expressing anger. Use of reflective listening and "I messages" were introduced as 
tools to use in dealing with anger. Members were asked to observe anger expression by men and women with whom they associated and as portrayed on television during the week so that they can compare their observations at the next meeting.

Session 5 - Members were asked what advice they would give parents about helping their children deal with anger, and what general advice they would give to today's teenagers about expressing anger. Members also were asked to discuss the most stressful events in their lives and how they dealt with those events. Sheehy's (1981) concept of adult passages was introduced.

Session 6 - The concept of the anger experience as a task was introduced (Novaco 1975), and problem solving techniques were suggested. Members were asked to respond to this concept. The leader summarized the content of the group discussions and asked members what they liked best and least about the group meetings.

\section{Collection of Data}

Group participants were solicited at senior citizen centers and in retirement centers by distributing flyers describing the groups and asking members to sign up at the activity director's office of their center or to call the examiner. The examiner met with prospective group members, verbally explained the study, and answered questions about 
the study. Those women who agreed to participate in the study completed the demographic data sheet and signed the consent form.

In two of the four groups formed for this study, members did not know each other well and did not socialize with each other outside the group. In the other two groups, however, members did know each other and a few members did see other socially. Group I consisted of four women who met in a retirment center hospitality room for the six sessions. All four nembers lived in the center. After the fifth session, however one of the members became very ill and did not complete the questionnaires, and after the sixth session, another member of this group moved to live with her brother. Only two members of this group completed the ASR and $B D I$ and the follow-up administration of these instruments .

Group II consisted of four members and met in an apartment center complex where two of the members lived. Another member lived in a house near the apartment center, and the fourth member lived in a retirement center complex in the same city. All four members completed the six sessions, the posttests, and the one month follow-up tests. Group III met in a senior citizen center. This group was composed of eight members, however, one of the members suffered a stroke and moved to a convalescent center. Members of this group met each other every week at the 
center and thus were acquainted with each other. Seven nembers of this group completed the six sessions, the posttests and the one month follow-up tests.

Group IV met in a retirement center complex and all four of the members of this groups lived in the complex, however, the complex is large and they did not know each other prior to the group sessions. All four members completed the six sessions, the posttests and the one month follow-up tests.

At the end of the last group session, group members were asked to complete the Anger Self Report and the Beck Depression Inventory during the following week. The examiner collected the instruments from members the following week.

Four weeks following the last group session, the ASR and the BDI were again delivered to members of the treatment groups for the follow-up comparison. The examiner picked up the completed inventories one week later.

The examiner solicited control group volunteers from senior citizen centers and retirement centers in the North Texas Area. The examiner delivered packets containing the letter of explanation, the Consent Form, the Demographic Data Sheet, the ASR, and the BDI to 31 women. Twenty seven of these packets were picked up by the examiner, and four were mailed to the examiner. From these 31 demographic data sheets, 17 women were selected for the matching control 
group.

\section{Procedure for Data Analysis}

The Static Group Comparison design was modified for this study by using a matching group for the control group. According to Campbell and Stanley (1963), the static group comparison design controls well for the internal sources of invalidity of history, testing, instrumentation and regression. However, a weakness in internal validity may occur in the areas of selection, mortality and interaction of selection with other variables. The design is also weak in external validity. By matching the treatment groups on variables relating to life satisfaction, external validity is increased, and invalidity resulting from mortality is lessened.

Variables upon which the treatment grolips and control groups were matched were determined by a search of the literature of correlates of life satisfaction, and also the variables found to distinguish older adults with depressive symptoms from older adults who do not appear depressed. Members of the treatment and control groups were matched on age, type of residence, marital status, educational level, occupation, and perceived health.

Hypotheses 1 through 6 were tested by performing a t-test for irdependent samples comparison of the mean posttest scores of the treatment and matching control groups 
(Borg \& Gall, 1983; Ferguson, 1981). The .05 level of significance was used to reject the null hypotheses. Results of the post treatment tests and the one month follow-up tests of the treatment group were analyzed using the t-test for correlated samples (Ferguson, 1981).

Because of the lack of data concerning the topic of this study, an additonal analysis of variance was done on the matching variables and the $A S R$ and BDI. For this comparison, the post treatment ASR and BDI scores of the 17 members of the treatment groups, the scores of the 17 matchirg control group and the scores of the other 14 volunteers who were not used for the matching group were pooled so that a comparison was made between 48 subjects' scores on the ASR, the BDI, and the matching variables of age, marital status, type of residence, educational level, occupational level, and perceived health. 


\section{RESULTS AND DISCUSSION}

This chapter presents the results of the data analysis and includes a discussion of the findings. Recommendations based upon the findings are also presented.

\section{Analysis of Data}

Hypothesis 1 stated that no significant difference would exist between the post test scores of the treatment groups and matching control groups on the Beck Depression Inventory. The t-test comparison of means for the two groups is presented in Table 3.

Table 3

T-Test of the Mean Differences Between the Treatment and Control Groups on the Beck Depression Inventory

\begin{tabular}{lccccc}
\hline & $\begin{array}{c}\text { Number } \\
\text { of cases }\end{array}$ & Mean & $\begin{array}{c}\text { Standard } \\
\text { Deviation }\end{array}$ & $\begin{array}{c}t \\
\text { Value }\end{array}$ & $\begin{array}{c}2-\text { Tail } \\
\text { Prob. }\end{array}$ \\
\hline Treatment & 17 & 12.76 & 4.116 & 2.66 & .013 \\
Cortrol & 17 & 8.35 & 5.905 & & \\
\hline
\end{tabular}

There is a significant difference between the means of the treatment group and the matching control group. However, the direction is opposite of that expected on the 
basis of previous research. The treatment group has significantly higher mean scores on the BDI than the control group. Since there is a significant difference between the groups, Hypothesis 1 is rejected.

Hypothesis 2 stated that no significant difference would exist between the posttest scores of the treatment and control groups on the Awareness of Anger subscale of the Anger Self Report Scale. Table 4 shows the results of the $\underline{t}-$ test analysis of the Awareness scores. There is no significant difference between the two means, therefore, Hypothesis 2 is retained.

Table 4

T-test Analysis of the ASR Awareness of Anger Subscale

\begin{tabular}{lccccc}
\hline & $\begin{array}{r}\text { No. of } \\
\text { Cases }\end{array}$ & Mean & $\begin{array}{c}\text { Standard } \\
\text { Deviation }\end{array}$ & $\begin{array}{c}t \\
\text { Value }\end{array}$ & $\begin{array}{c}2-t a i l \\
\text { Prob. }\end{array}$ \\
\hline Treatment & 17 & -13.59 & 12.19 & .26 & .796 \\
Cortrol & 17 & -14.59 & 10.12 & & \\
\hline
\end{tabular}

Hypothesis 3 stated that no significant difference would exist between the posttest scores of the treatment and control groups on the Total Expression of Anger subscales of the ASR. Table 5 shows the results of the t-test analysis of the Total Expression of Anger subscale scores. There is no significant difference between the means of the two groups and, therefore, Hypothesis 3 is retained. 
Table 5

T-test of the Mean Difference Between Treatment and Control Groups on ASR Total Expression of Anger Subscale

\begin{tabular}{lccccc}
\hline & $\begin{array}{c}\text { Number } \\
\text { of Cases }\end{array}$ & Mean & $\begin{array}{c}\text { Standard } \\
\text { Deviation }\end{array}$ & $\begin{array}{c}t \\
\text { value }\end{array}$ & $\begin{array}{c}\text { 2-tail } \\
\text { Prob. }\end{array}$ \\
\hline Treatment & 17 & -35.588 & 17.794 & -.59 & .556 \\
Control & 17 & -32.2941 & 14.326 & & \\
\hline
\end{tabular}

Hypothesis 4 stated that no significant difference would exist between the posttest scores of treatment and control groups on the Guilt subscale of the ASR. Table 6 shows the results of the $t$-test difference of the treatment and control group on the Guilt subscale of the ASR. There is no significant difference between means of the two groups, therefore, Hypothesis 4 is retained.

Table 6

T-Test of the Mean Difference Between the Treatment and Control Groups on the ASR Guilt Subscale

\begin{tabular}{lccccc}
\hline & $\begin{array}{c}\text { Number } \\
\text { of Cases }\end{array}$ & Mean & $\begin{array}{l}\text { Standard } \\
\text { Deviation }\end{array}$ & $\begin{array}{c}t \\
\text { value }\end{array}$ & $\begin{array}{c}\text { 2-tail } \\
\text { Prob. }\end{array}$ \\
\hline Treatment & 17 & -8.647 & 7.921 & & \\
Control & 17 & -8.118 & 7.598 & -.20 & .796 \\
\hline
\end{tabular}

Hypothesis 5 stated that no significant difference would exist between the two groups on the Condemnation of Anger subscale. Table 7 shows the t-test comparison of the means of the treatment and control groups on the ASR 
Condemation of Anger subscale. There is no significant difference between means of the two groups, therefore, Hypothesis 5 is retained.

Table 7

T-Test Aralysis of the Mean Differences of the Treatment and Control Groups on the ASR Condemnation of Anger Subscale

\begin{tabular}{lccccc}
\hline & $\begin{array}{c}\text { Number } \\
\text { of Cases }\end{array}$ & Mean & $\begin{array}{c}\text { Standard } \\
\text { Deviation }\end{array}$ & $\begin{array}{c}t \\
\text { value }\end{array}$ & $\begin{array}{r}\text { 2-tail } \\
\text { Prob. }\end{array}$ \\
\hline Treatment & 17 & -1.529 & 8.545 & .38 & .71 \\
Control & 17 & -2.588 & 7.874 & & \\
\hline
\end{tabular}

Hypothesis 6 stated that no significant difference would be found between the treatment and control groups on the Mistrust subscale of the ASR. Table 8 presents results of the t-test analysis of the two groups on the Mistrust subscale. There is no significant difference between the two means, therefore, Hypothesis 6 is retained.

Table 8

T-Test Analysis of the Mean Differences Between Ireatment and Control Groups on the ASR Mistrust Subscale

\begin{tabular}{lccccc}
\hline & $\begin{array}{c}\text { Number } \\
\text { of cases }\end{array}$ & $\begin{array}{c}\text { Standard } \\
\text { Deviation }\end{array}$ & $\begin{array}{c}t \\
\text { Value }\end{array}$ & $\begin{array}{c}\text { 2-tail } \\
\text { Prab. }\end{array}$ \\
\hline Treatment & 17 & -10.88 & 12.639 & 1.00 & .325 \\
Control & 17 & -14.76 & & 1.00 \\
\hline
\end{tabular}


Follow-Up Data

The posttest scores of the treatment group were compared with one month follow up scores using a th-test for correlated samples (Ferguson, 1981). Table 9 shows the means, standard deviations and $\underline{t}$-test results for comparisons of the posttest and one month follow up of the Awareness of Anger, Total Expression of Anger, Guilt, Condemation of Anger and Mistrust Subscales of the ASR. There are no significant changes between the posttest and the follow-up test on any of the subscales of the Anger Self Report.

Table 9

T-Test Comparison of the Means of the Treatment Group Scores on the ASR Immediately Following the Sixth Group Meeting and One Month Later

$$
\text { Posttest Follow up } t \text { value Prob. }
$$

\begin{tabular}{lrrrrrr} 
Subscale & Mean & SD & Mean & SD & \\
\hline Awareness & -13.59 & 12.19 & -11.59 & 11.57 & -.98 & .34 \\
Tot. Exp. & -35.59 & 17.79 & -36.00 & 19.90 & .14 & .89 \\
Guilt & -8.65 & 7.92 & -7.41 & 9.03 & -.65 & .52 \\
Condemnation & -1.53 & 8.55 & -1.47 & 6.40 & -.04 & .97 \\
Mistrust & -10.88 & 12.64 & -12.82 & 9.04 & 1.10 & .29 \\
\hline
\end{tabular}


of the posttest and the one month follow-up scores on the BDI. There is no significant difference between the BDI taken immediately following the group meetings, and the one month follow-up BDI.

Table 10

Paired Samples t-test of the Post-treatment and One Month Follow-up Treatment Group Scores on the BDI

\begin{tabular}{lccccc}
\hline & $\begin{array}{c}\text { Number } \\
\text { of Cases }\end{array}$ & Mean & $\begin{array}{l}\text { Standard } \\
\text { Deviation }\end{array}$ & $\begin{array}{c}t \\
\text { value }\end{array}$ & $\begin{array}{r}\text { 2-tail } \\
\text { Prob }\end{array}$ \\
\hline BDI No. 1 & 17 & 12.76 & 4.12 & 1.95 & .068 \\
Follow UP & 17 & 10.35 & 4.17 & & \\
\hline
\end{tabular}

\section{Additional Analysis of Data}

Due to the shortage of available information on the experience and expression of anger in people aged 65 and older, a one-way analysis of varience was performed using the matching variables and each of the subtests of the Anger Self Report and the Beck Depression Inventory. Test results of the 17 treatment group members, the 27 matching control members, and test results of 14 women who volunteered for for the study but were not part of the matching group were combined, making a total of 48 test results which were analyzed to determine if there were differences on the ASR, the BDI, and matching variables. Since there are more than two catagories in the matching variables of educational level, place of residence, occupation, and marital status 
the Scheffe multiple comparison procedure was used to determine significant differences between groups when one-way analysis of variance yielded a significant Fmatio. This procedure is the most conservative of the multiple range procedures, and was chosen because of the small number of subjects in some groups (Huck, Cormier \& Bounds, 1974).

To perform the analysis of variance, educational and occupational levels were reorganized into three groups. Group I was composed of non-high school graduates; Group 2 consisted of women who graduated from high school and those with some college education, and Group 3 combined women with college degrees with women who also had post graduate training. In the same manner, the corresponding occupational levels (Hollingshead, 1975) were grouped. Occupational levels $1,2,3$, and 4 were combined into Group 1; occupational levels 5 and 6 were placed into Group 2; and levels 7 and 8 were combined into Group 3.

Table 11 shows results of the analysis of variance of general expression of anger and age. There is a significant difference between age of subject and the General Expression of Anger subtest. The 23 women in the group of women who were age 75 and older scored significantly lower on the General Expression of Anger subtest than the 25 women aged 65 to 75 .

Table 12 shows the results of an analysis of variance of the difference between age and the Beck Depression Index. 
The older group of women, those aged 75 and over, scored significantly higher on the BDI than the group of women aged 65 to 75 .

Table 11

Analysis Variance of General Expression of Anger and Age

\begin{tabular}{cccccc}
\hline Source & df & $\begin{array}{c}\text { Sum of } \\
\text { Squares }\end{array}$ & $\begin{array}{c}\text { Mean } \\
\text { Squares }\end{array}$ & $\begin{array}{c}\text { F. } \\
\text { Ratio }\end{array}$ & $\begin{array}{c}F \\
\text { Prob. }\end{array}$ \\
\hline Between groups & 1 & 405.6419 & 405.6419 & 7.5659 & .0085 \\
Within groups & 46 & 2466.2748 & 53.6147 & & \\
\hline
\end{tabular}

Table 12

Analysis of Variance of the Beck Depression Inventory and Age

\begin{tabular}{cccccc}
\hline Source & df & $\begin{array}{l}\text { Sum of } \\
\text { Squares }\end{array}$ & $\begin{array}{l}\text { Mean } \\
\text { Squares }\end{array}$ & $\begin{array}{c}\text { F. } \\
\text { Ratio }\end{array}$ & $\begin{array}{c}\text { F. } \\
\text { Prob. }\end{array}$ \\
\hline Eetween Groups & 1 & 132.8705 & 132.8705 & 4.82 & .0333 \\
Within Groups & 46 & 1268.6087 & 27.5784 & &
\end{tabular}

Table 13 shows results of the analysis of variance of educational levels and the Guilt subscale. There is a significant difference between the Guilt subscale and educational level. Scheffe's Multiple Range Test revealed that Group 2, composed of high school graduates and women who also have some college education, and Group 3, composed of college graduates and post graduates, are significantly different on the Guilt Subscale. Group 3 had scores that 
show significantly less guilt than Group 2. Group 1's scores are not significantly different from those of Group 2 or Group 3. There were 8 women in Group 1, 28 women in Group 2, and 12 women in Group 3 .

Tabie 13

Analysis of Variance of Educational Level and ASR Guilt Subscale

\begin{tabular}{lrrrrr}
\hline Source & D.F. & $\begin{array}{c}\text { Sum of } \\
\text { Squares }\end{array}$ & $\begin{array}{c}\text { Mean } \\
\text { Squares }\end{array}$ & $\begin{array}{c}\text { F } \\
\text { Ratio }\end{array}$ & $\begin{array}{c}F \\
\text { Prob. }\end{array}$ \\
\hline Between Groups & 2 & 483.6964 & 241.8482 & 4.50 & .0165 \\
Within Groups & 45 & 1416.2202 & 53.6938 & & \\
\hline
\end{tabular}

Table 14 shows results of a one-way analysis of variance on marital status and the Mistrust subscale of the ASR. There were 26 widowed women, 10 married women, and 12 divorced women. Results of Scheffe's Multiple Range Test showed that married women scored significantly lower on the Mistrust subscale than divorced women, and widowed women's scores did not differ signficantly from married or divorced women's scores.

Results of the analysis of variance of the Condemation of Anger subscale and type of residence are shown in Table 15. Twenty-six women live in houses, 16 women live in retirement center apartments, and 6 live in apartments. Scheffe's Multiple Range Test reveals that those women living in houses scored significantly lower on the 
Condennation of Anger subscale than did the women living in retirement center apartments. The group of women who Iive in apartments do not differ significantly from other groups on scores of Condemnation of Anger.

Table 14

Analysis of Variance on Marital Status and the Mistrust Subscale of th'e ASR

\begin{tabular}{cccccc}
\hline Source & D.F. & $\begin{array}{c}\text { Sum of } \\
\text { Squares }\end{array}$ & $\begin{array}{c}\text { Mean } \\
\text { Squares }\end{array}$ & $\begin{array}{c}F \\
\text { Ratio }\end{array}$ & $\begin{array}{c}F \\
\text { Prob. }\end{array}$ \\
\hline Between Groups & 2 & 1735.5833 & 867.7917 & 7.29 & .0018 \\
Within Groups & 45 & 5353.6667 & 119.9704 & & \\
\hline
\end{tabular}

Table 15

Analysis of Variance of Type of Residence and Condemation of Anger Subscale

\begin{tabular}{cccccc} 
Source & D.F. & $\begin{array}{c}\text { Sum of } \\
\text { Squares }\end{array}$ & $\begin{array}{c}\text { Mean } \\
\text { Squares }\end{array}$ & $\begin{array}{c}F \\
\text { Ratio }\end{array}$ & $\begin{array}{c}F \\
\text { Prob. }\end{array}$ \\
\hline Between Groups & 2 & 474.2163 & 237.1082 & 4.1857 & .0215 \\
Withir Groups & 45 & 2549.0962 & 56.5466 & & \\
\hline
\end{tabular}

Table 16 shows results of analysis of variance of perceived health and the Condemnation of Anger Subscale of the ASR. The 34 women who perceive themselves in good or excellent health show scores significantly lower on the Condemnation of Anger subscale than the 14 women who peroeive their health as poor or Eair. 
Table 16

Analysis of Variance of Perceived Health and the

Condemnation of Anger Subscale of the ASR

\begin{tabular}{ccccccc}
\hline Source & D.F. & $\begin{array}{c}\text { Sum of } \\
\text { Squares }\end{array}$ & $\begin{array}{c}\text { Mean } \\
\text { Squares }\end{array}$ & $\begin{array}{c}F \\
\text { Ratio }\end{array}$ & $\begin{array}{c}F \\
\text { Prob. }\end{array}$ \\
\hline Between Groups & 1 & 268.7537 & 268.7537 & 4.4881 & .0396 \\
Within Groups & 46 & 2754.5588 & 59.8817 & & \\
\hline
\end{tabular}

Comparison with ASR Validation Groups

Table 17 shows Anger Self Report Scores of the 17 women in the treatment groups, and 17 women in the matching control groups compared with the two groups on whom the ASR was validated (Zelin, Adler \& Myerson, 1972). An independent one-way analysis of variance of the means of the RSR subtests of the four groups revealed significant differences among the treatment and control groups and the inpatient and student groups on all of the subtests. Both the treatment and control group of this study scored signficantly lower on awareness of anger and expression of anger than the psychiatric inpatient group and the student group upon whom the ASR was validated. Scheffe's Multiple Range Test was used to determine significant differences between groups. Tables 18 through 24 show results of the multiple range tests for the four groups on the seven ASR subtests. 
Table 17

ASR Means and Standard Deviations for Treatment and Control Groups and for Zelin. Adler \& Myerson's Validation Sample

82

Psychiatric

67

17

17

F

Inpatients Students Treatment Control Prob.

\begin{tabular}{|c|c|c|c|c|c|}
\hline Awareness & 3.78 & 11.74 & -13.59 & -14.59 & .000 \\
\hline S.D. & $(16,1)$ & $(11.3)$ & $(12.19)$ & $(10.12)$ & \\
\hline Ger. Exp. & -4.82 & .80 & -13.47 & -14.12 & .000 \\
\hline S.D. & $(10.4)$ & $(9.3)$ & $(6.86)$ & $(7.65)$ & \\
\hline Verbal & -1.46 & 6.58 & -11.06 & -8.59 & .000 \\
\hline S.D. & $(11.6)$ & $(8.2)$ & $(8.33)$ & $(7.04)$ & \\
\hline Guilt & 3.13 & -5.69 & -8.65 & -8.12 & .000 \\
\hline S.D. & $(12.4)$ & $(11.1)$ & $(7.92)$ & $(7.6)$ & \\
\hline $\begin{array}{l}\text { Condemn- } \\
\text { ation of } \\
\text { Anger }\end{array}$ & -6.80 & -11.34 & -1.53 & -2.59 & .000 \\
\hline S.D. & $(9.9)$ & $(7.6)$ & $(8.55)$ & $(7.87)$ & \\
\hline Mistrust & -6.57 & -2.99 & -10.88 & -14.76 & .006 \\
\hline S.D. & $(14.7)$ & $(12.8)$ & $(12.64)$ & $(9.84)$ & \\
\hline Total Exp. & -11.34 & 5.66 & -35.59 & -32.29 & .000 \\
\hline S.D. & $(24.3)$ & $(18.4)$ & $(17.79)$ & $(7.04)$ & \\
\hline
\end{tabular}

df-Between Groups 3

df-Within Groups 179 
Table 18

Results of the Multiple Ranqe Test for Awareness of Anqer

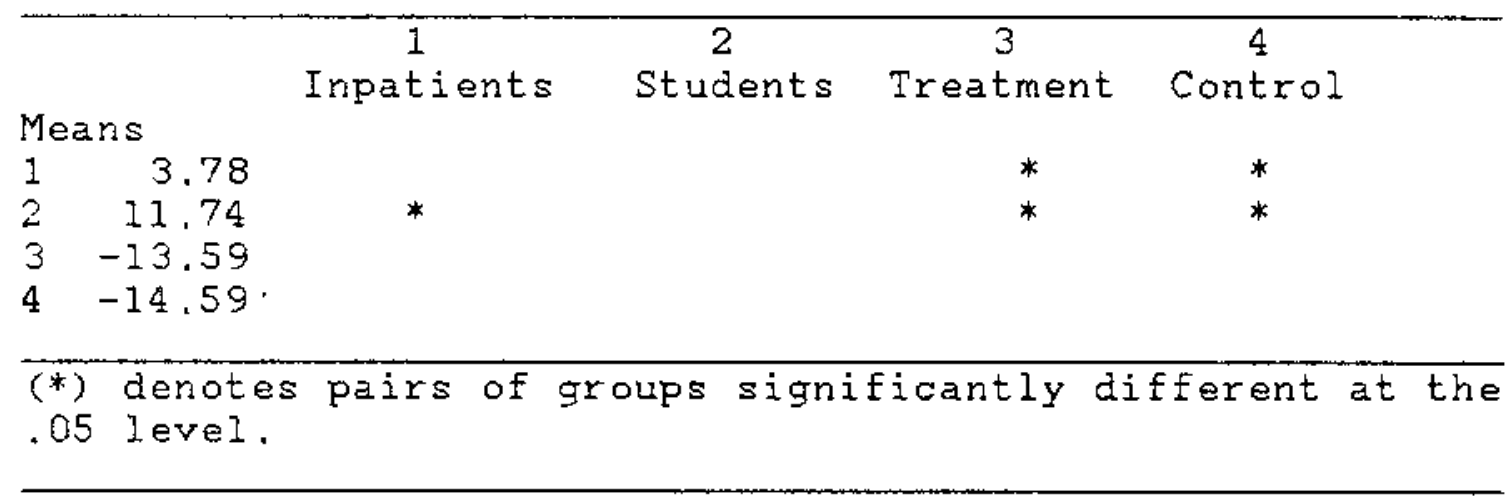

Table 19

Results of the Multiple Range Test for General Exp. of Anger

Means

Inpatients Students Treatment Control

$1-4.82$

2.80

$3-13.47$

$4-14.12$

(*) Tenotes pairs of groups significantly different at the .05 level

Table 20

Results of the Multiple Range Test for Verbal Exp. of Anger

\begin{tabular}{|c|c|c|c|c|}
\hline 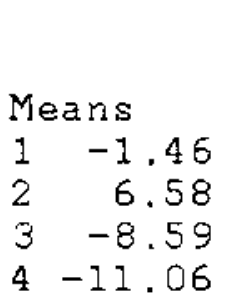 & $\frac{1}{\text { Inpatients }}$ & $\frac{2}{\text { Students }}$ & $\begin{array}{c}3 \\
\text { Treatment } \\
* \\
*\end{array}$ & $\begin{array}{c}4 \\
\text { Control }\end{array}$ \\
\hline $\begin{array}{l}\text { (*) Denot } \\
.05 \text { level }\end{array}$ & pairs of & $p s s$ & $t 1 y$ & ferent at the \\
\hline
\end{tabular}


Table 21

Results of the Multiple Range Test for Guilt

\begin{tabular}{lcccc}
\hline & Inpatients & Students & Treatment & Control \\
Means & & & & $*$ \\
$1 \quad 3.13$ & & & $*$ & \\
$2-5.69$ & & & \\
$3-8.65$ & & & \\
$4-8.12$ & & & \\
(*) Denotes pairs of groups & significantly different at the \\
.05 level &
\end{tabular}

Table 22

Results of the Multiple Range Test for Condemation of Anger

\begin{tabular}{|c|c|c|c|c|}
\hline 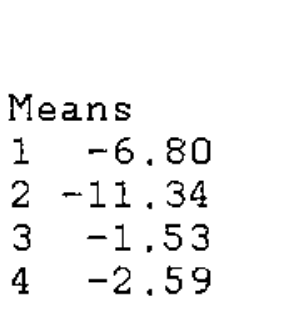 & $\begin{array}{c}1 \\
\text { Inpatients } \\
*\end{array}$ & $\begin{array}{c}2 \\
\text { Students }\end{array}$ & $\begin{array}{c}3 \\
\text { Treatment } \\
*\end{array}$ & $\begin{array}{c}4 \\
\text { Control }\end{array}$ \\
\hline $\begin{array}{l}\text { (*) Denotes } \\
.05 \text { level }\end{array}$ & pairs of & groups sign & icantly & fferent at the \\
\hline
\end{tabular}

Table 23

Results of the Multiple Range Test for Mistrust

\begin{tabular}{|c|c|c|c|c|}
\hline 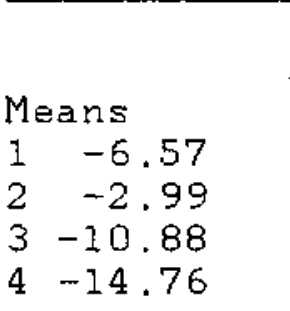 & Inpatients & $\begin{array}{c}2 \\
\text { Students }\end{array}$ & $\begin{array}{c}3 \\
\text { Treatment }\end{array}$ & $\begin{array}{c}4 \\
\text { Control }\end{array}$ \\
\hline $\begin{array}{l}\text { (*) Derotes } \\
\text {.05 level }\end{array}$ & Pairs of & groups sig & icantly d & erent at the \\
\hline
\end{tabular}


Table 24

Results of the Multiple Range Test for Total Expression.

\begin{tabular}{|c|c|c|c|c|}
\hline $\begin{array}{lr}\text { Means } \\
1 & -11.34 \\
2 & 5.66 \\
3 & -32.29 \\
4 & -35.59\end{array}$ & $\begin{array}{c}1 \\
\text { Inpatients }\end{array}$ & $\begin{array}{c}2 \\
\text { Students }\end{array}$ & $\begin{array}{c}3 \\
\text { Treatment } \\
* \\
*\end{array}$ & $\begin{array}{c}4 \\
\text { Control } \\
* \\
*\end{array}$ \\
\hline $\begin{array}{l}\text { (*) Denotes } \\
.05 \text { level }\end{array}$ & pairs of & groups sigl & cantly di & erent at \\
\hline
\end{tabular}

On the Verbal Expression of Anger subscale, the inpatient group shows less verbal expression than the student group and the treatment group, but do not differ from the control group. The student group shows more verbal expression than the other three groups. The inpatient group shows significantly more guilt than the student group, the treatment group or the control group. The student, treatment and control groups do not differ significantly from each other. The student group also shows less condemation of anger than the other three groups. On the Mistrust subscale, only the student and control groups differ significantly. The student group shows less mistrust than the control group. On the Total Expression of Anger subscale, the treatment and control groups show significantly less expression of anger than the inpatient or student groups. Also, the inpatient group shows significantly less expression of anger than the student 
group.

\section{Summary of Results}

For subjects in this study, there is a significant difference between the treatment and matching control group on the Beck Depression Inventory, although the difference is contrary to the expected direction since the treatment group scores are significantly higher on the BDI than the control group scores, Results show no significant differences between treatment and control groups on the Anger Self Report subscales of Awareness of Anger, Expression of Anger, Guilt, Condemnation of Anger or Mistrust. There are no significant differences on the post-treatment scores and one-month follow up scores on the Anger Self Report subscales or the Beck Depression Inventory.

An analysis of variance of the matching variables and the pooled test scores of the total sample, i.e. the 31 women from whom the 17 matching group was chosen and the 17 womer in the treatment groups, reveal significant differences between some of the matching variables. Scores of both the treatment and control groups differ significantly from groups upon whom the ASR was validated.

Discussion

The experience of group discussions centering on 
increasing awareness and expression of anger did not bring about a change in awareness of anger or expression of anger in the six week time period of this study. This lack of change for the women in this study contrasts with the studies of Hazaleus and Deffenbacher (1986) and Novaco (1979), who did find a reduction in anger following short term group counseling. The difference in these findings may indicate that reduction of anger and anger control are more amenable to short term treatment than are increasing awareness and expression of anger. The difference in results may also indicate that this population of older women does not feel the need to change their awareness and expression of anger. As Altholz (1980) suggested, older people may regard anger expression as ineffective in producing desired outcomes, especially in restricted environments, and the aging process may lead to less awareness and less expression of anger.

The significanlty higher mean BDI scores for this study's treatment group, when compared with the control group, may be due to the anxiety caused by increased awareness, or insight, into patterns of expressing anger. Many theories acknowledge that awareness or insight may intitially be painful, as people recognize that they have problems and these problems may have antecedents in their childhood (Ellis, 1984; Mosak, 1984; May \& Yalom, 1984; Simkin \& Yontef, 1984). High depression scores for the 
treatment group might also be the result of normal depression which occurs with the termination of a group. Ekl of (1984) suggested that the termination phase of a group may be especially difficult for older adults because of the accumulation of losses suffered when friends and family members died or became ill.

The women in this study were slower to develop group cohesiveness than is generally expected in groups (Yalom, 1975). With a group of subjects who are psychologically unaware, or unused to talking about themselves, more time and intital training in communication skills may be necessary to establish group cohesiveness. Cohesiveness is essential for effective group counseling (Yalom, 1975), and has been identified as one of the most important contributors to alleviation of depression in group counseling by Hoberman, Lewinsohn, and Tilson (1988). In a study of 40 men and women with a mean age of 38.3 , percieved group cohesiveness measured at sessions 3 and 7 in a 12-week Coping with Depression Course was one of the factors associated with reduction in depression levels. The measure of group cohesiveness obtained in the first session was not a significant predictor of success in this study. Rather, it was the building of a feeling of closeness to members of the group which was important in alleviation of depression. Ore of the discussions which group members reported they enjoyed most was the discussion of their family of 
origin, family constellation and the patterns of communication in that family. Many women were able to see patterns in communication styles and expression of anger in their families of origin and their children's families. These discussions are similar to Butler and Lewis' (1977) Life Review and allowed participants to explore the patterns in their lives in a way that is applicable to their futures. Many of the participants were eager to talk about their lives and recognized that guided reflection on their past can enharce the present.

The finding of significantly less expression of anger and significantly more depression in women in this study aged 75 and older seems to support the suggestion of a probable link between expression of anger and depression. This trend was not found in the women aged 65 to 75 .

The women in this study had scores significantly lower on the Anger Self Report than those of the ASR norm groups, which seems to suggest that older women are less aware of anger, express anger less, and condemn anger more than younger people. Indeed, the findings of this study, that older women are less aware of anger and express anger less than younger people, that women living in retirement centers condemn anger more than women living in houses, that women who perceive themselves in poor or fair health condemn anger more than women in good and excellent health, appear to support Novaro's (1979) theory that when people perceive 
they have little control over a situation, withdrawal and helplessness are more likely to be the chosen behavior. Conversely, when people perceive they have control, anger is the more likley expression.

The mistrust demonstrated by the divorced women in this study supports the findings of Kitson, Lopata, Holmes and Meyering (1980) that divorcees view life somewhat differently than widows. According to their findings, divorcees had a more negative attitude to iife without a spouse than did widows, and were more likely to feel that they had lost status, and were taken advantage of. Moreover, divorcees were more prone to feel suspicious of others than were widows.

Though this study found perceived health related to condemnation of anger, health status was not related to depression in this sample of women. This finding is contrary to that of Tutaj (1975), who, in a study of depression among residents of nursing and retirement homes, found that depression increased with age and was related to health status.

The findings of this study suggest that older women do not have more guilt than other populations. When compared to Zelin et al.'s norming group (1972), the women in this study did not differ on the Guilt subscale from the student population, and they showed less guilt than Zelin's Fopulation of impatients. Women in this study who graduated 
from college and those who also had postgraduate training showed significantly less guilt than the group of women who graduated from high school and those who had some college education. The group of women who did not graduate from high school did not differ from the other two educational groups on the Guilt subscale.

\section{Related Findings}

It took women in this study longer to establish rapport with each other and to be comfortable talking about themselves, especially their feelings, than is generally expected in the group process (Yalom, 1975), and, therefore, there was an initial tendency to talk in generalities rather than specifics. Group members had a difficult time talking about things that made them angry. They began by talking about incidents they read in the newspaper and saw on the television newscasts which made them really angry, such as brutality to policemen, child abuse, etc. As the groups progressed, group members did talk about incidents which were hurtful and which angered them. On occasion, they recalled incidents from their adolescent or young adults years. As the groups progressed, members talked about frustrations, unfairnesses, and extremely stressful events in language more commonly used to describe anger. However, they resisted labeling these emotions as anger. For example, one woman spoke of "cursing under her breath" but 
did not label the feeling as anger.

When asked to recall how their parents expressed anger, most women remembered their mother as never getting angry or staying angry. Only three women reported that their mother had habitually expressed extreme anger. Members varied more in their memory of the frequency and intensity of their fathers' anger. Some women remembered their fathers as frequently very angry while three women said their father was never very angry and never raised his voice to his family.

Generally, the women reported that they were not encouraged to express anger when they were children. One woman reported that her father taught her: "It was okay to be angry, but to control it." Another woman reported that she had a rather pampered childhood and a terrible temper, but said she had mellowed over the years and seldom gets angry now.

Most members reported that they more closely resembled their mothers in their expression of anger than their fathers. Several women reported that their anger expression modified as they aged. The reasons for this, they said, were: (1) wisdom--they had learned when it was important to get angry; (2) having fewer things to do now, so fewer frustrations; and (3) a more restricted life style, fewer people to interact with, and thus fewer opportunities for anger. 
In one of the retirement center groups, when pressed about incidences of anger in the center, the group mentioned several times when residents got angry at their neighbors. They talked also about a tendency to report incidents like Ioud noises to the manager rather than confronting their neighbors or even asking them to lower the noise level. All members agreed it was harder for women of their generations to be assertive than it is for women today. They grew up in a time when people were not encouraged to express feelings. They talked about the difficulty of expressing anger today. One woman reported that sometimes she does not say anything when she is angry for fear of saying too much. Several women said that when they became really angry, they prayed about it and eventually, through prayer, were able to forget the incident. Another woman reported that it takes so much energy to be angry she chooses not to be angry unless it is really important. She says she cannot afford to waste energy on anger.

Members were asked to respond to the anger arousing incident of waiting in a long line when someone cuts in front of you. Only one woman reported that she would be confrontive. She said she would tell the person in charge that a person had cut in line. Everyone else said they would be irritated, but that they would not say anything. Some of the explanations for not saying anything were: "Someone who will do that would not listen anyway," "I have 
nothing better to do, so I may as well stand in line," "I'm afraid I'll say too much and really make the person who cut in Iine angry."

The focus of the lives of most of the women in this study had been their families. Only 2 of the 17 members of the treatment groups were childless. Even though all but three of the women worked outside the home, their work was secondary to their roles as homemakers. Some of the women are still very involved in the lives of their children and grandchildren, while others raxely see their children.

Group members talked about difficult times in their lives. Many members talked about the most difficult periods being related to health, either their own health or the illness of a spouse. Three of the members had husbands with Alzheimer's Disease. The latter experience is extremely stressful and all three experienced little support from friends or family throughout the time that they had to care for their husbands. They reported that few people really seemed to understand how difficult this experience is, the intense pain of losing someone while they are physically present.

The losses suffered throughout their lives were a source of great stress. The deaths of any family members, especially husbands and children, were still recalled with great pain. Having a circle of friends outside one's family was seen as one of the sources of life satisfaction. On the 
other hand, it was painfully recognized that as one ages, one frequently loses these friends either by death or by moving away. Frequently expressed was missing siblings or friends with whom they had a "shared past:" "Someone who laughs at the same things you laugh at," and with whom an accumulation of experiences are shared.

Difficulty in forming new friendships seemed to be a common problem. Perhaps because it takes so much energy, becalase it is difficult to find people with common interests and because, as one woman put it, "you learn not to get too close to your neighbors, because they leave." Because of the accumulation of losses experienced, the women seemed hesitant to risk further loss by becoming close to others. Of the women in this study who maintain close associations with their families, six members reported the greatest stresses in their lives today relate to problems in their childrens' lives. The ability to help their children by listening to their problems is gratifying to them.

There was a general agreement among these women that men have more trouble expressing feelings than do women. Many women reported the belief that it is especially difficult for men to express anger and grief. They discussed their fathers' and husbands' expression of emotions. One woman reported that her husband's childhood had been so difficult that he clung very closely to her and relied on her and their children for all his emotional support. 
Several women discussed the position of "being in the middle" between husbands and children, and the difficulty of maintaining peace in the family. They also were able to see patterns in their expression of anger and the way their children express anger.

Several women reported that it would have been nice to talk to a counselor or someone during stressful times in their lives. They also reported a hesitancy to talk to friends about family matters for fear of possibly embarrassing their husband or children.

Some difference was observed between the aged 65 to 75 group and the 75 and older group. The younger group frequently verbalized that it is better to talk about anger than to suppress it, and several of them expressed the belief that it is good for parents to argue in front of their children, so the children can learn how to argue. Many of the older group described feelings usually associated with anger, but did not label these feelings as anger.

As women in these groups described their earlier and current lives, a definite tendency to focus their lives around relationships with others, especially family, was noted. Therefore a developmental task of this age, especially the 75 and older age range, appears to be adjusting to the loss of relationships and finding ways of developing new, meaningful relationships to replace the 
losses. As Greenberg (1987) suggested, successful adjustment to old age may involve focusing on new aspects of oneself, one's feelings and abilities. It appears that this inward focus can be more purposful if undertaken in a group setting which allows one to verbalize feelings and get feedback from others. All the women voiced the need to stay active, to associate with people. Several members who had suffered from depression in the past reported that the only way they were able to combat the depression was to force themselves to get out and be with other people. Another need frequently expressed was the need to talk about meaningful topics. A comment often made was how tiresome it grows hearing their peers talk about health concerns.

Hearing impairment interferred with group interaction somewhat. Many of the women in the treatment groups had difficulty hearing and needed to read lips in order to hear. This hearing limitation made the relaxation exercises difficult, since they had to concentrate on watching intently in order to hear what was said. Also, the lighting in the room was especially important because of the need to see the speaker's face to understand what was being said. Group members who had difficulty hearing were reluctant to ask other group members to repeat or to talk louder. Impressions were that women who participated in this study enjoyed the opportunity to interact with other women and to talk about their experiences. Many described the 
group experience as important to them and voiced the desire to continue the meetings. One group made plans to continue meeting to support each other.

\section{Conclusions and Recommendations}

Based upon the findings of this study, it seems reasonable to conclude that older women do differ from younger populations in their awareness and expression of anger. All the ASR scores for the women in this study are significantly lower than the younger groups upon which the ASR was normed. Since women aged 75 and older were significantly more depressed and expressed anger less than women in the 65 to 75 age group, it appears that around age 75, susceptibility to depression increases, and the likelihood of positive anger expression decreases.

None of the women in this study appeared to be in debilitating distress, since none of the scores on the BDI were in the range classified as moderately depressed. Replication of the study using group counseling centering upon increasing awareness and expression of anger as methods to relieve depression with a population of women suffering from depression might better delineate the relationship between anger and depression.

Replication of the study over a longer period of time to allow the necessary time to build cohesiveness among group members and time to explore and deal with anger 
awareness and expression would be beneficial. Apparently, more time is needed both for older adults to build group cohesiveness and for group members to increase awareness of anger than is needed to reduce anger outbursts among younger populations.

A longitudinal study of anger would help to determine whether differences between generations are due to different influences related to cohort differences, or whether, as people age, they express anger less and become more depressed. Differences between the groups upon which the ASR was validated (Zelin, Adler \& Myerson, 1972) indicate that a significant difference exists between those groups and the group in this study. Comparisons of different age groups together with longitudinal studies would help to determine if attitudes, awareness and expression of anger change with age, or whether differences are due to environmental and historical influences.

Finally, replication of the study with men would aid in understanding how men and women experience anger and whether they experience anger differently. Women in the aged 65 and older age group clearly believe that they experience and express anger differently than men. The theory of a difference in men and women's experience of anger is prevalent and is frequently related to women's lack of economic independence and oppessive influences in the socialization of women (Cline-Naffaiger, 1974, \& Lerner, 
1985). Knowledge of differences in the experience and expression of anger between different cohorts and between men and women in older generations will increase understanding and thus enhance relationships. 
APPENDIX 
Hollinghead's Educational and Occupational Scales

Level of School Completed

Score

Less than seventh grade

Junior high school ( 9 th grade)

1

Partial high school (10th or 11th grade)

High school graduate (whether private preparatory, parochial, trade, or public school)

Partial college (at least one year) or specialized 5 training

Standard College or University graduation

Graduate professional training (graduate degree)

2

3

4

6

7

\section{Occupational Scale}

Score 9 Higher Executives, Proprietors of Large Businesses, and Major Professionals

Score 8 Administrators, Lesser Professionals, Proprietors of Medium-Sized Businesses

Score 7 Smaller Business Owners, Farm Owners, Managers, Minor Professionals

Score 6 Technicians, Semiprofessionals, Small Business Owners

Score 5 Clerical and Sales Workers, Small Farm and Business Owners

Score 4 Smaller Business Owners, Skilled Manual Workers, Craftsmen, and Tenant Farmers

Score 3 Machine Operators and Semiskilled Workers

Score 2 Unskilled Workers

Score 1 Farm Laborers/Menial Service Workers 
OutIine of Group Discussions

Due to the counseling orientation of group sessions, the outline provided is somewhat flexible, to allow time for group interaction of participants. However, to insure uniformity of the group experience between groups, the starred items will be covered in each group.

Session I

* Group Orientation: 'Introductions

Discuss group meetings and confidentiality of group discussions.

* Have group members write down two incidents about which they are angry and rate the intensity of anger on a scale of 1-10 with 1 being 1 east anger and 10 being very intense anger.

* Discuss angry feelings. Discuss how people feel when they are angry, and how one's body feels when angry.

* Discuss how to distinguish between anger, fear, and hurt. 
* Instruct farticipants to think about their parents and describe how their mother acted when she was angry, and how their father acted when he was angry.

* Ask how the group members themselves express anger, and ask whether they are more like their Father or Mother in the way they express anger.

* Homework assignment: Ask group members to keep a record of the number of times they get angry during the week, and the intensity of angry feelings.

Session II

* Discuss homework, the times group members experienced anger and how intense the angry feelings were. Discuss common experiences of anger during the week. What common incidents make group members angry.

* Ask members to describe how they felt when they were angry, after the angering event, and how they feel now as they think about the event.

Ask group members to think about who is most commonly the instigator of angering events. Ask members to think about how much control they feel they have over the events, and what they wish they had done before, during and 
following the event.

* Explain Ellis's Rational Emotive Psychology. A, B, Cs, A the activating event, $B$, the Beliefs and $C$ the consequences.

Session III

* Read an anger-arousing incident and ask members to respond to the situation. Ask them to describe the feelings which they experience as they listen to the story. Ask them to discuss similar angry experiences. Talk about suggestions for handling such situations.

* Do push button technique: Ask members to close their eyes and recall a time when they were angry. Say, remember the incident, and think about how you felt, think about your body and where you experience the anger, remember what you said to yourself during the angry episode. Notice your breathing as you remember the angry feelings. Do you feel, hurt as well as anger, fear as well as anger, helplessness as well as anger,. . Do you feel out of control, or that someone else is out of control?

Now with your eyes still closed, think of a pleasant time, possibly a time when the same people were involved. Think of a time when you felt free of anger, you felt good about 
how you handle yourself, about the way you feel about yourself, a time when you feel comfortable with those near you and very capable and self confident. Notice your body now, how do you feel? What do you say to yourself when you feel good about your relationships.

* Discuss the way we control how we feel, and discuss the thirgs we say to ourselves, our beliefs about angry feelings and the best way to express such feelings.

* Do relaxation training technique.

\section{Session IV}

* Discuss beliefs about expressing feelings and beliefs about being angry. Have participants list all the things they believe they are justified in being angry about.

* Recall again how parents behaved when they were angry. Ask members to recall messages in their families about being angry and about the correct way to express anger. Ask about how they acted as a small child when their parents were angry. How do they feel today when others around them are angry, when people are angry at them? How do their children behave when they are angry? 
Can they see any patterns about being angry in their families?

Discuss reflective listening and reflecting feelings.

Explain "I" messages. Ask group members to practice using "I" messages this week and also to practive reflective listening.

Session $V$

* Discuss, or review, the use of "I" messages, and reflective listening.

* Ask members to discuss the advice they would give teenagers today about expressing their anger.

* Ask members to discuss the advice they would give young married couples about how to handle anger.

* Ask members to discuss advice they would give parents about teaching their children how to handle anger. Ask members what advice they would give each other about expressing anger.

Talk about viewing angering experiences as a task. What do 
they want to accomplish from angry episodes. Outline problem solving behavior.

Session VI

* Discuss, or review, viewing anger experiences as a task, and considering what they hope to accomplish from this task. Outline problem solving behavior.

* Share feelings about the group, ask members what they learned from each other. Ask what part of the group experience they liked best.

* Ask members to share the most anger provoking experiences they have now, what angered them most in the past. Ask them to consider how they would like the anger episodes to be resolved.

Ask the group to brainstorm likely outcomes of angering episodes. Ask the group to react to these experiences.

Ask group members to go over again the problem solving technigues.

Evaluate the group experience and Complete the BDI and the ASR . 


\section{Letter of Explanation}

We know today that we continue to grow and learn throughout our lives, and we are finding that each age of life can be rewarding. One way to learn about ourselves and others is through sharing ideas and beliefs in discussion groups.

I am a doctoral student in counseling at North Texas State University and $I$ am doing a study which involves sharing experiences concerning emotions, especially awareness and expression of anger. The study will involve groups of eight to ten adults meeting for one hour a week for six weeks. During these weekly meetings you will have the opportunity to learn and share experiences with other group members and with a trained group leader.

Discussion groups such as these are widely used across the country, and most people who participate believe them to be a valuable experience. In additon to the benefits to you, however, your participation in this study will contribute to helping us understand ourselves and how we continue to learn and change throughout our lives.

Two separate groups will be formed from those who apply. One will begin meeting right away and one will begin meeting 10 weeks later. In order to satisfy statistical requirements, assignments to the groups will be random. I will notify you of your group's meeting dates after everyone has signed up. Members of both groups will be asked to complete a demographic data sheet and two questionnaires which will be confidential.

There is no charge for participation, and participation is voluntary. You may withdraw at any time. If you have any questions, please call Wanda Johnson at 383-1123. If you choose to participate, please fill out the attached consent form and the data sheet, and $I$ will contact you about the first meeting. 
Demographic Data Sheet

Name

Address

Telephone Number

Age

Marital Status: Check One Physical Health: Check One Married

Single

Widow

Divorced

Excellent

Good

Fair

Poor

Residence: Please check one Live in an apartment

---- Live in a retirement center apartment

-_- Live in a house

-_-_- Live in a duplex

Do you live with someone else?

or alone?

Formal education: Please check the highest level of education completed.

6-8 years, elementary school

- Completed Junior High

-_-_- High School graduate 1-2 years of college

College graduate Graduate school or post graduate courses

Please describe your occupation, or your former occupation if you are retired.

Husband's occupation

Approximately how many years were you employed?

Are you currently seeing a counselor? 
Informed Consent

I agree to participate in a study conducted by Wanda Johnson, a doctoral candidate at North Texas State University. I understand and agree that I am to participate in 6 weekly, 1 hour group discussions which will focus on the experience and expression of anger. I understand that these sessions will be led by a leader trained in group communications. I understand that my participation is voluntary and that I may withdraw at any time.

I also understand that I will be asked to complete a demographic data sheet and two questionnaires, and that the information gathered will be included with that of others in the reporting of the study, and my identity will be kept completely annonymous.

I have heard a clear explanation and understand the nature and purpose of this study. I have read the above and I agree to participate in this study.

Signature

Investigator

Witness 
THE ANGER SELF REPORT SCALE

We would like you to consider carefully the following statements and indicate as accurately as you can how it applies to you: There are no right or wrong answers, we just want to know how you feel.

Please mark next to each statement according to the amount of your agree or disagreement by using the following scale:
1 slight agreement
-1 slight disagreement
2 moderate agreement
-2 moderate disagreement
3 strong agreement
$-3 \quad$ strong disagreement

Mark all statements!

If a statement is unclear to you, place an " $x$ " next to it in the margin, but mark it anyway. If a statement somehow does not apply to you, place a "?" next to it in the margin, but mark it anyway.

Please begin. 
1. I get mad easily.

2. I am often inclined to go out of my way to win a point with someone who has opposed me.

3. People are only interested in you for what they can get.

4. People will hurt you if you don't watch out.

5. I never feel hate towards members of my family.

6. Often people are friendly when they want something but drop you when they no longer need you.

7. No one wants to hurt me.

8. People should never get angry.

9. Some of the people closest to me take secret satisfaction in my misfortunes.

10. It's right for people to express themselves when they are mad.

11. Some of my family have habits that bother and annoy me very much.

12. When I get mad, I say nasty things.

13. Even when my anger is aroused, I don't use strong language.

14. If I am mad, I really let people know it. 15. Sometimes i feel that i could injure someone. 16. I will criticize someone to his face if he deserves it. 
17. I rarely hate myself.

18. I get into fist fights about as often as the next person.

19. People should never get irritated.

20. I find that I carnot express anger at someone until they have really hurt me badly.

21. I think I'm a pretty nice person.

22. Even when people yell at me, I don't yell back.

23. At times $I$ have a strong urge to do something harmful or shocking.

24. I have many quarrels with members of my family.

25. Often people who are really out to get you act as nice as can be on the outside.

26. I hardly ever punish myself.

27. Feeling angry is terrible.

28. I never do anything right.

29. It doesn't make me angry to have people hurry me.

30. If I don't like somebody, I will tell him so.

31. I have physically hurt someone in a fight.

32. At times I feel like smashing things.

33. Whatever else may be my faults, I never knowingly

hurt another person's feelings.

34. I really wish I could be a better person.

35. I usually am satisfied with myself.

36. I find it easy to express anger at people. 
37. My parents never made me angry.

38. I can depend on people when in trouble.

39. Even when someone does something mean to me, I don't let him or her know I'm upset.

40. At times I hurt a person I love.

41. People do not generally disappoint me.

42. I hardly ever feel like swearing.

- 43. I couldn't hit anyone even if I were extremely angry.

-___ 44 . I'm just no good.

4. 45. I never think of killing myself.

-__-_ 46. I hardly ever get angry.

_-_ 47. Even though I disapprove of my friends' behavior, I just can't let them know.

- 48. I find it hard to think badly of anyone.

-_-_ 49. I can think of no good reason for ever hitting anyone.

50. When people are angry, they should let it out.

51. I blame myself if anything goes wrong.

52. I am rarely cross and grouchy.

53. In spite of how my parents treated me, I didn't get angry.

54. I could not put someone in his place even if he needed it. 
55. It's easy for me not to fight with those I love. 56. When I really lose my temper, I am capable of slapping someone.

57. If someone annoys me, I am apt to tell him what I think of him.

58. Our major institutions are falling apart. 59. People are as thoughtful of my feelings as I am of theirs.

60. It's useles to get angry.

61. Generally you can depend on people to help you. 62. If someone crosses me, I tend to get back at him. 63. I think little of people who get angry. 64. I often feel disaster is just around the corner. 


\section{REFERENCES}

Aldrich, C. K. (1964). Personality factors and mortality in

the relocation of the aged. Gerontologist, $4,92-93$.

Altholz, J.A. (1982). Anger in the aged (Doctoral

dissertaion, Florida State University). Dissertation

Abstracts International, 42, $2629 \mathrm{~A}$.

Aries, E. (1976). Interaction patterns and themes of male,

Eemale, and mised groups. Small Group Behavior, 7, 7-18.

Averil1, J. R. (1982). Anger and aggression: An essay on

emotion, New York: Springer-Verlag. Beck, A, T. (1967).

Bailey, K. D. (1978). Methods of social research. New York:

The Free Press.

Beck, A. T. (1967). Depression: Clinica1, experimental, and

theoretical aspects. New York: Springer-Verlag.

Beck, A. T., Ward, D. H., Mendelson, M., Mock, J., \& Erbaugh,

J. (1961). An inventory for measuring depression.

Archives of General Psychiatry, 4, 561-571.

Biaggio, M. K. (1980). Assessment of arousal. Journal

of Personality Assessment, 44, 289-298.

Blazer, D., Hughes, D. C., \& George, L. K. (1987). The

epidemiology of depression in an elderly community

population. The Gerontologist, 27, 281-287.

Borg, W. R., \& Gall, M. D. (1983). Educational research. New

York: Longrnan Inc. 
Brody, E. M. (1985). Mental and physical health practices of older people. New York: Springer.

Buss, A. H., \& Durkee, A. (1957). An inventory for

assessing different kinds of hostility. Journal of

Consultirg Psychology, 21, 343-349.

Busse, E., \& Blazer, D. (1980). Disorders relating to biological

furctioning. In E. Busse \& D. Blazer, (Eds.). Handbook of

geriatric esychology, New York: Van Nostrand Reinhold.

Butler, R., \& Lewis, M. (1977). Aging and mental health.

St. Louis: C. V. Mosby.

Campbell, D. T., \& Stanley, J. C. (1963). Experimental and

guasi-experimental designs for research. Boston: Houghton Mifflin.

Cline-Naffziger, D. (1974). Women's lives and frustration, oppression, and anger: Some alternatives. Journal of Counseling Psychology, 21, 51-56.

Dean, L. (1962). Anging and the decline of affect. Journal of Gerontology, $17,440-446$.

Dean, R. E. (1980). Negative reactions to the expression of anger as a factor in depression in college students (Doctoral Dissertation, Auburn University). Dissertation Abstracts International, $41,2315 \mathrm{~B}$.

Edwards, J. N., \& Klemmack, D. I. (1973). Correlates of life satisfaction: A re-examination. Journal of Gerontology,

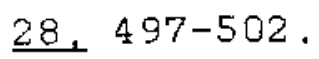

Eklof, M. (1984), The termination phase in group therapy: 
Implications for geriatric groups. Small Group Behavior. 15 . $565-571$.

Ellis, A. (1984). Rational emotive therapy. In R. Corsini

(Ed.) Current psychotherapies (PP. 196-238). Itasca, Il.: F.

E. Peacock.

Epstein I. J. (1976). Depression in the elderly. Journal of Gerontology. 31, 278-282.

Ferguson, G. A. (1981). Statistical analysis in psychology and education. New York; MaGraw-Hill.

Ferster, C. B. (1973). A functional analysis of depression.

American Psychologist, 28, 857-870.

Freud, S. (1917). Mourning and melancholia. In J.

Strachey (Ed.), The complete works of Sigmund Freud

(Standard Edition) London: Hogarth Press, PP. 73-102.

Friedman, A. S. (1970). Hostility factors and clinical

improvement in depressed patients. Archives of General

Psychiatry, 23, 524-537.

Friedman, A. S., \& Granick, S. (1963). A note on anger and aggression in old age. Journal of Gerontology, 18, 283-285. Gallagher, D., Breckenridge, J., Steinmetz, J., \& Thompson, I. (1983). The Beck Depression Inventory and research diagnostic criteria: congruence in an older population. Journal of Consulting and Clinical Psychology, 51, 933-934. Gallagher, D., Nies, G., \& Thompson, L. (1982).

Reliability of the Beck Depression Inventory with older adults. Journal of Consulting and Clinical Psychology, 50 , 
$152-53$

Gershon, E. S., Comer,. M., \& Klerman, G. L. (1968).

Hostility and depression. Psychiatry, 31, 224-235.

Goldfarb, A. I. (1975). Depression in the old and aged. In

F. F. Flach\&S. C. Draghil (Eds.), The nature and treatment

of depression (pp. 119-144). New York: John Willey \& Sons.

Greenberg, L. R. (1987) "Old wives' tales": Retrospective

views of elderly women. In R. Formanek \& A. Gurian (Eds.).

Women and depression $(272-295)$. New York: Springer

Publishing Co.

Gurland, B. J., (1976). The comparative frequency of

depression in various adult age groups. Journal of

Gerontology, 31, 283-292.

Hale, D. (1982). Correlates of depression in the elderly:

Sex differences and similarities. Journal of Clinical

Psychology, 38, 253-257.

Hasterok, J. B. (1973). A procedure for and the effects of

becoming aware of anger (Doctoral dissertation, University

of Florida). Dissertation Abstracts International, 34 .

$5678 B$

Hazaleus, S. L., \& Deffenbacher, J. L. (1986). Relaxation

and cognitive treatment of anger. Journal of Consulting and

Clinical Psychology. 54, 222-226.

Herry, J. (1976). Understanding the early pathophysiology

of essential hypertension. Geriatrics, 31, 59-72.

Hoberman, H, Lewirsohn, P., \& Tilson, M. (1988). Group 
treatment of depression: Individual predictors of outcome. Journal of Consulting and Clinical Psychology. 56, 393-398. Hoffman, R. A. (1977). Affect assertion training, insight therapy and ward milieu: Effects on anger expression, locus of control and MMPI scores. (Doctoral dissertation, Georgia State University). Dissertation Abstracts International. 39, $383 B$.

Hollingshead, A. (1975). Four factor index of social status. (Available from: Department of Sociology, Yale University, P. O. Box 1965, New Haven, Ct. 06520). Huck, S. W., Cormier, W. H., \& Bounds, W. G. (1974). Reading statistics and research. New York: Harper \& Row. Jensen, G. D., \& Oakley, F. B. (1982). Ageism across cultures and in perspective of sociobilogic and psychodynamic theories. International Journal of Aging and Human Development, $15,17-26$. Kitson, G. C., Lopata, H. Z., Holmes, W. M., \& Meyering, S. M. (1980). Divorcees and widows: Similarities and differences. American Journal of Orthopsychiatry, 50, 291-301. Kleban, M. M., \& Brody, E. M. (1972). Prediction of improvement in mentally impaired aged: Personality ratings by social workers. Journal of Gerontology, $27,69-76$. Kutner, B., Fanshel, D., Togo, A. M., \& Langner, T. S. (1963). Factors related to adjustment in old age. In R. G. Kuhlen $\alpha$ G. G. Thompson (Eds.), Psychological studies of human. development (pp. 591-603). New York: Meredith Publishing Co. 
Lambert, M. J., Hatch, D. R., Kingston, M. D., \& Edwards, B. C. (1986). Zung, Beck, and Hamilton rating scales as measures of treatment outcome: A meta-analytic comparison. Journal of Consulting and Clinical Psychology, 54, 54-59. Lerner, H. G. (1985). The dance of anger. New York: Harper \& Row.

Lopata, H. Z. (1978). The absence of community resources in support systems of urban widows. Family Coordinator, 27. 383-388.

May, R., \& Yalom, I. (1984). Esistential psychotherapy. In R. Corsini (Ed.) Current psychotherapies (pp.354-391). Itasca, Il.: F. E. Peacock. Medler, B. W: (1980). A selected review. In G. Landreth \& R. C. Berg (Eds.), Counseling the elderly (pp. 451-463). Springfield, I1.: Charles C. Thomas.

Menninger, K. (1938). Man against himself. New York:

Harcourt, Brace \& World.

Miller, M. (1979). Suicide after sixty: The final

alternative. New York: Springer.

Moon, J.R., \& Eisler, R. M. (1983). Anger control: An experimental comparison of three behavioral treatments. Behavior Therapy, 14, 493-505.

Mosak, H. (1984). Adlexian Psychotherapy. In R. J. Corsini (Ed.), Current psychotherapies (PP. 56-107). Itasca, I1.: F. E. Peacock.

Nelson, D. W. (1982). Alternative images of old age as the 
bases for policy. In B. I. Neugarten (Ed.), Age or need?

(pp. 131-169). Beverly Hilis: Sage Publications.

Noel, P. S. (1980). Effective anger versus cathartic anger

in the treatment of depression (Doctoral dissertation,

Fordham University). Dissertation Abstracts International. 40, $5823 B$.

Novaco, R. W. (1975). Anger control: The development and evaluation of an experimental treatment. Lexington, MA.:

Lexington Books/D. D. Heath.

Novaco, R. W. (1977). Stress inoculation: A cognitive

therapy for anger and its application to a case of

depression. Journal of Consulting and Clinical Psychology. 45, $600-608$.

Novaco, R. W. (1978). Anger and coping with stress. In J. P. Foreyt \& D. P. Rathjen, (Eds.). Cognitive behavior therapy, New York: Plenum Press.

Novaco, R. W. (I979). Treatment of chronic anger through cognitive and relaxation controls. Journal of Consulting and Clinical Psychology, 44, 681 .

Palmore, E., \& Luikart, C. (1972). Health and social factors related to life satisfaction. Journal of Health \& Social Behavior, $13,68-80$.

Rahdert, E. R. (1980). Manifestations of anger in clinically depressed women (Doctoral dissertation, Purdue University). Dissertation Abstracts International, 42 , $388 \mathrm{~B}$. 
Rogers, D. (1979). The adult years, Englewood Cliffs, N. J.: Prentice Hall.

Rothenberg, A. (1971). On anger. American Journal of Psychiatry, 128, 454-460.

Salzman, D., \& Shader, R. I. (1978). Depression in the elderly. Relationship between depression, psychologic defense mechanisms and physical illness. Journal of the American Geriatrics Society. 26, 253-260.

Sarason, I. G. (1961). Intercorrelations among measures of hostility. Journal of Clinical Psychology, 17, 192-195.

Sargent, S. S. (1982). Therapy and self-actualization in

the later years via nontraditional approaches.

Psychotherapy, Theory Research and Practice, 19, 522-531. Sartorius, N., \& Ban, T. A. (1986). Assessment of depression, Berlin, Germany: Springer-Verlag. Schless, A. P., Mendels, J., Kipperman, A., \& Cochrane, C. (1974). Depression and hostility. Journal of Nervous and Mental Disease, 159, 91-100.

Sheehy, G. (1981). Pathfinders, New York: Bantam Books. Simkin, J. S., \& Yontef, G. M. (1984). Gestalt therapy. In R. Corsini (Ed.) Current psychotherapies (pp. 279-319). Itasca, Il.: F. E. Peacock. Tutaj, G. A. (1975). The effectiveness of group counseling in alleviating depression among the aged. Dissertation Abstracts International, $36,2653$.

Turner, B. F., Tobin, S. S., \& Eieberman, M. A. (1972). 
Personality traits as predictors of institutional adaptation among the aged. Journal of Gerontology, 27, 61-68. Walen, S. R., DiGiuseppe, R., \& Wessler, R. L. (1980). A practioner's guide to rational-emotive therapy. New York: Oxford Press.

Weissman, M. M., Klerman, G. L., \& Paykel, E. S. (1971).

Clinical evaluation of hostility in depression. American Journel of Psychiatry, 128, 261-166.

Wellman, F. E., \& McCormack, J. (1980). Counseling with

older persons: A review of outcome research. The

Counseling Psychologist, 12, 81-95.

Wenz, F. V. (1980). Aging and suicide: Maturation or

cohort effects? International Journal of Aging and Human

Development, 11, 297-305.

Winefield, H. R. (1981). Anger expression in the picture

Erustration study uner stressful conditions. Journal of

Personality Assessment, 45, 370-374.

Yalom, I. D. (1975). The theory and practice of group

psychotherapy. New York: Basic Books.

Zarit, S. H. (1980). Aging and mental disorders. New

York: The Free Press.

Zelin, M. L., Adler, G., \& Myerson, P. G. (1972). Anger

self-report: An objective questionnaire for the measurement of aggression. Journal of Consulting and Clinical

Psychology, 39, 340 .

Zelin, M. L., Adler, G., \& Myerson, P. G. Addendum to anger . 
self-report: An objective questionnaire for the measurement of aggression. Correspondence received from M. L. Zelin, Tufts University, Medford, MA 02135.

Ziegler, M., \& Reid, D. W. (1983). Correlates of changes in desired control scores and in life satisfaction scores among elderly persons. International Journal of Aqing and Human Development, 16, 134-146. 